\title{
Animals and Babies: \\ How the vulnerable teach us empathy and compassion
}

\author{
Avril A. Gaastra
}

\author{
LLB, BA (Canterbury University) \\ Graduate Diploma of Teaching (Primary), \\ Postgraduate Diploma in Education and Professional Development \\ (Victoria University of Wellington)
}

Submitted in total fulfilment of the requirements of the degree of Master of Education (by Thesis only)

The Melbourne Graduate School of Education The University of Melbourne

Produced on archival quality paper

November 2010 


\begin{abstract}
Compassion and empathy have historically embodied what are considered to be some of the best elements of humanity. The processes whereby we come to know the internal stage of another and respond with sensitive care are of enormous importance for our life together (Batson, 2009). It is not surprising, then, that in recent years, there has been growing interest in the potential of empathy and compassion as critical values to foster in children. Yet despite this growing recognition, there remains relatively little information addressing how empathy and compassion might be addressed in teaching. An overriding argument of this thesis is that education in and for caring values - in this case empathy and compassion - has critical significance for personal, social and global wellbeing.

To investigate how these values might be taught, this study explores approaches to developing empathy and compassion within two primary school programs. The programs are The Roots of Empathy (RoE), a social and emotional learning (SEL) program that draws on the presence of a baby to foster empathy development in students, and the Voiceless Animal Clubs, which sought to develop in students the values of compassion and respect for animals. Guided by themes and models drawn from the literature on empathy and compassion, this thesis develops an approach for analysing empathy and compassion in these programs, which construes them as a synthesis of cognitive, affective and behavioural elements.
\end{abstract}


To explore these issues, a qualitative research approach has been employed, and two case studies developed based on each of the programs. The two case studies were informed by interviews with four Roots of Empathy instructors, and five Animal Club teachers, and were supplemented with secondary and contextual material. The purpose was not to evaluate the programs, but to identify and explore some tangible 'signposts' within the teaching of empathy and compassion, which may have application in other settings.

Throughout this thesis, two key arguments are developed and these are elaborated in the final chapter, along with some potential implications from this study. Firstly, two types of approach are explored with reference to their significance within the teaching of empathy and compassion. It is argued that a focus on 'relationships of caring' with vulnerable others, (in this case babies and animals) offers an engaging and experiential model for empathy and compassion education; and further that the concept and practice of 'compassionate advocacy' offers a means for supporting important outcomes for students and for society. Secondly, it is argued that the teaching of compassion and empathy would benefit from specific attention to developing their cognitive, affective and behavioural elements and that this, in turn, would support the development of empathy and compassion as authentically felt and acted-upon values. 


\section{DECLARATION}

This is to certify that

(i) the thesis comprises only my original work towards the Masters,

(ii) due acknowledgement has been made in the text to the material used,

(iii) the thesis is 36,070 words as approved by the Melbourne Graduate School Of Education

Signature:

Avril Anne Gaastra

Date: 


\section{ACKNOWLEDGEMENTS}

I would like to thank the following people for their support during the writing of this thesis. Firstly, I would like to thank to my wonderful partner Mike for his advice, support and companionship over the last two years. I could not have undertaken this without you.

Special thanks to my supervisor, Julie McLeod, for her ongoing support, time and knowledge. I am especially grateful for her consistently kind and encouraging response in the face of new directions and uncertainties.

Thanks to the staff at the Melbourne Graduate School of Education for their assistance throughout this amazing learning opportunity. Thanks to those who generously offered their time, or reading tips (thanks especially to $\mathrm{Mr}$ Michael McBain and Dr Rod Fawns).

Thanks to the inspirational teachers and instructors I interviewed for this project, who invested so much time, energy and belief in fostering the caring potential of children.

My ongoing appreciation goes out to my family for always encouraging me and supporting me in my different endeavours. Loving thoughts to Niwa, who I thought of often whilst writing my thesis.

\section{Correspondence}

Any correspondence regarding this thesis can be directed to the following email address:

avril.gaastra@yahoo.com 


\section{CONTENTS}

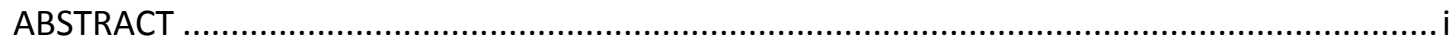

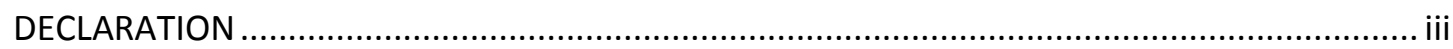

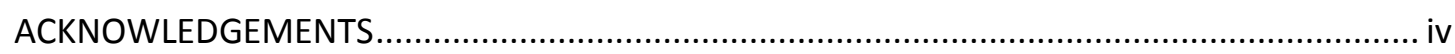

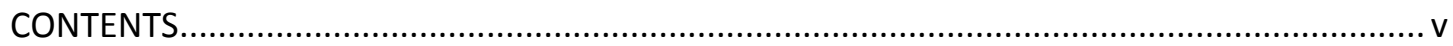

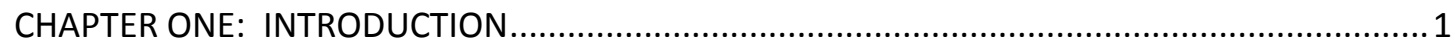

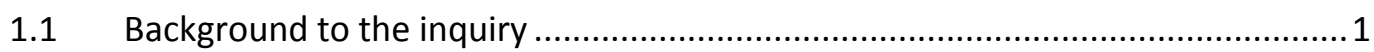

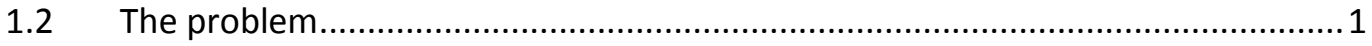

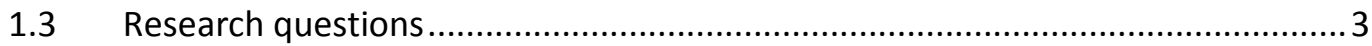

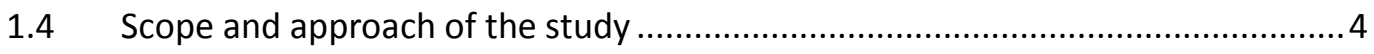

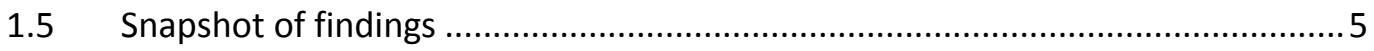

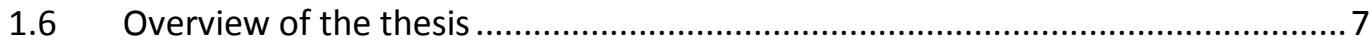

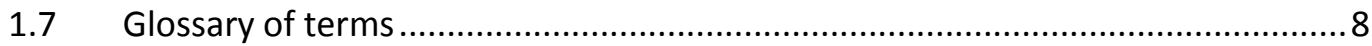

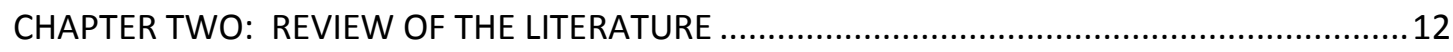

2.1 Part One - Teaching caring in our schools......................................................12

2.2 Part Two - Empathy and compassion ……...................................................20

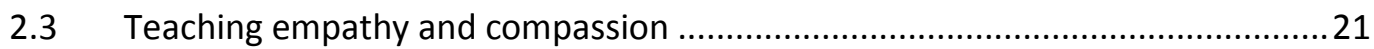

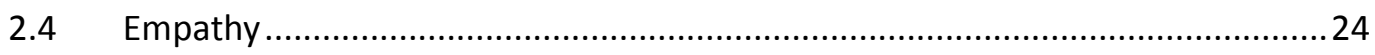

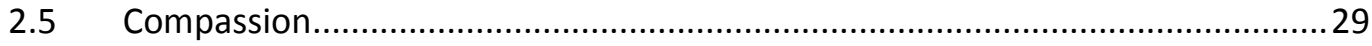

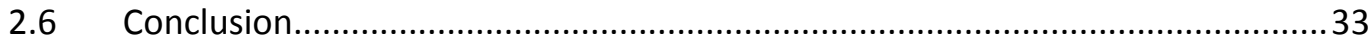

CHAPTER THREE: METHODOLOGICAL APPROACH AND STUDY DESIGN ................................ 34

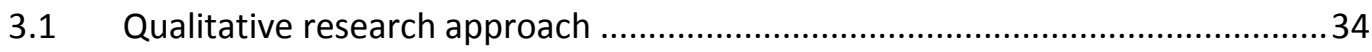

3.2 Case study within the qualitative paradigm ........................................................ 35

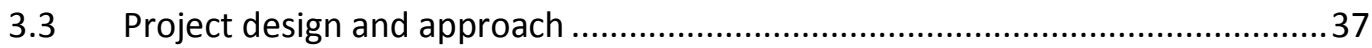

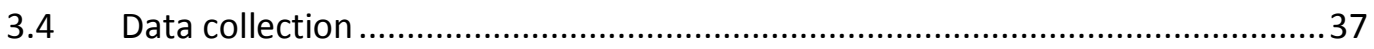

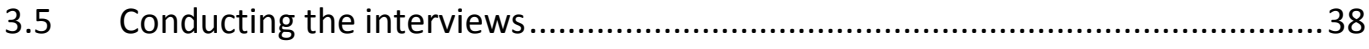

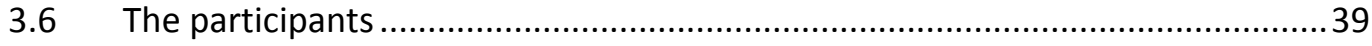

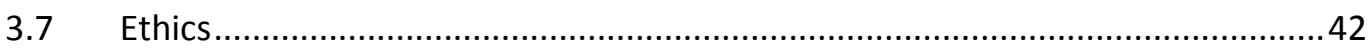




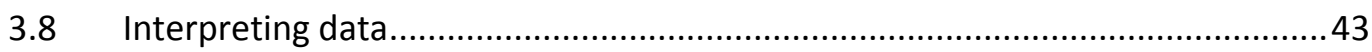

3.9 Limitations and challenges of the research ..................................................... 44

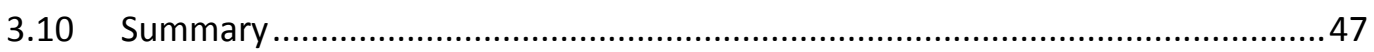

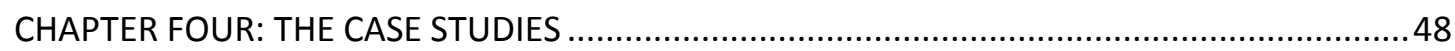

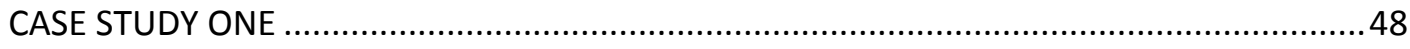

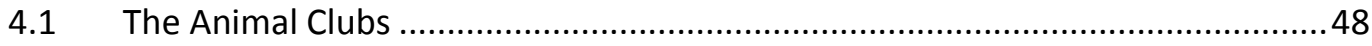

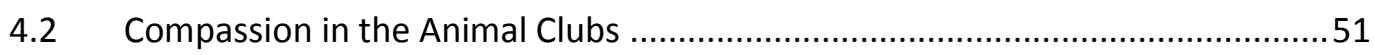

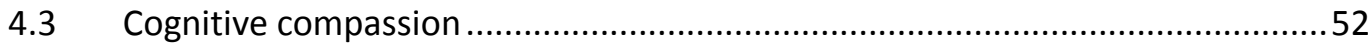

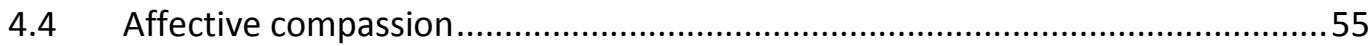

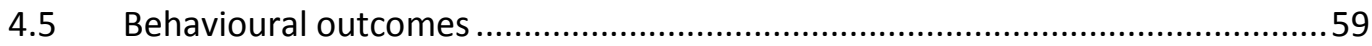

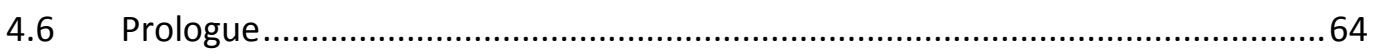

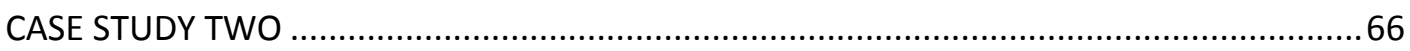

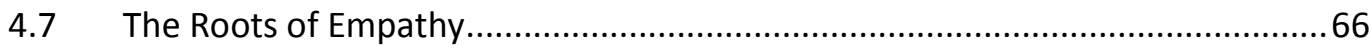

4.8 Empathy development in the Roots of Empathy program................................71

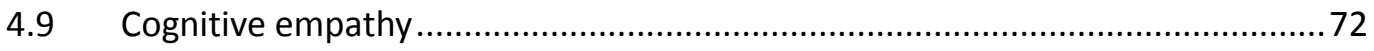

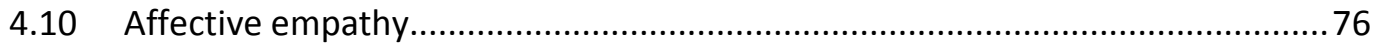

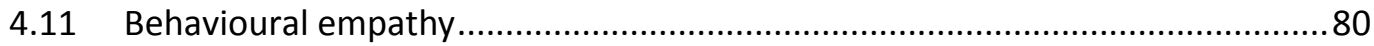

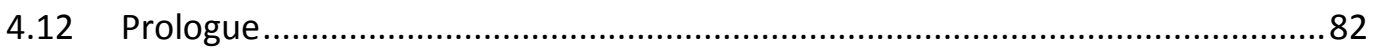

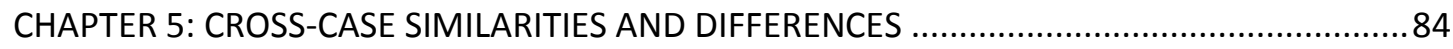

5.1 Empathy and compassion as cognitive, affective and behavioural

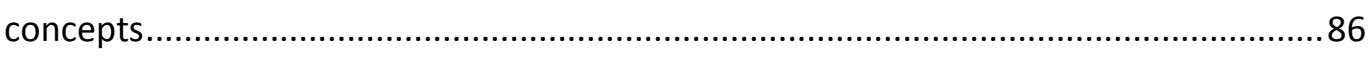

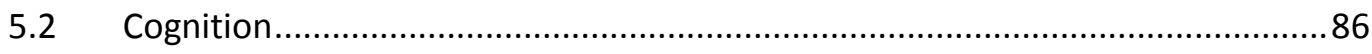

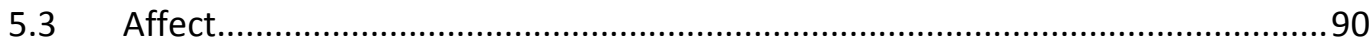

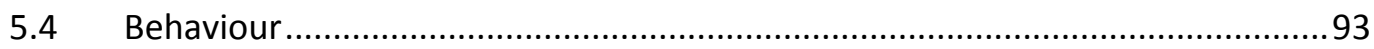

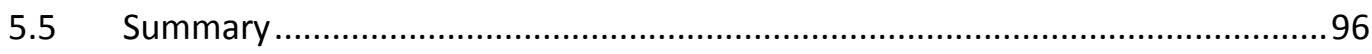

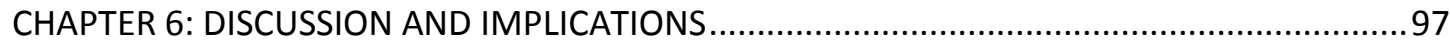

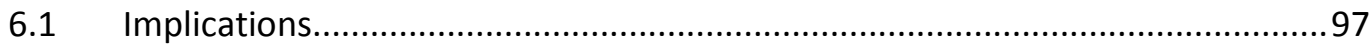

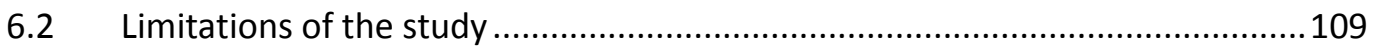

6.3 Recommendations for further research ..................................................... 111

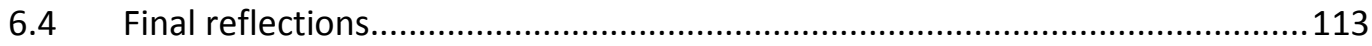

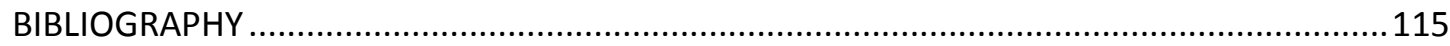




\section{CHAPTER ONE: INTRODUCTION}

\subsection{Background to the inquiry}

This study explores the possibilities for educating empathic and compassionate dispositions as a tangible investment in fostering more caring and humane futures. The specific focus in this study has been guided by my own experiences as a classroom teacher, including brief efforts to address social, emotional and moral learning with students. These highly affective fields are perhaps the most difficult to navigate for the inexperienced teacher because of the way in which they blend cognitive (thinking), affective (feeling), and behavioural elements into teaching and learning. The important nature of this work has fuelled my desire to explore two specific models of caring education in depth, in order to examine how efforts to develop empathic and compassionate dispositions might be approached.

This study has also been driven by my personal belief in the vital role education should play in fostering caring values in students. In seeking to contribute to the ongoing dialogue about the role of caring, empathy and compassion in our classrooms, I am driven by the knowledge that education is not a static activity. In this setting, ongoing conversations about the role of schools in creating more caring citizens and futures will help reshape education as a site of 'struggle and hope' (Ayers, 2003).

\subsection{The problem}

Within the background reading for this study, two major concerns have emerged from the varied literature on social, emotional and moral learning. Firstly, it is hard to overlook the concern that is often expressed in relation to the perceived moral decline facing our society (De Roche \& Williams, 
1998; Kenan, 2009; Mitchell, 2004; Wringe, 2006). These concerns about the 'deteriorating' social and moral state of our society are typically focused on an increasingly negative story revealed through social trends and indicators on crime, poor parenting and poor social and emotional functioning (Danaher, Brown, \& Slate, 2008; Kay, 1975; Vriens, 2000). The second issue relates more specifically to the education sector. Current political rhetoric supports the notion that the well-rounded student is competent, not only in an academic sense, but also in terms of physical, social, emotional, moral, and spiritual development (MCEETYA, 2008). Yet a raft of commentators express concern about the way education fails to foster the caring potential of generations of children. This failure, which is often attributed to an unrelenting focus on academic outcomes, operates to the detriment of social, emotional and moral education (Forrester, 2005; Gordon, 2003; Rosiek, 2003; Zins, Bloodworth, Weissberg, \& Walberg, 2007). Whilst there is some understanding of the importance of fostering positive values in students, together with sound social and emotional skills, in my view we still remain insufficiently attentive to this learning in schools.

In the face of these concerns, this study proposes to look in depth at two primary school programs which support specific forms of empathy and compassion education. Despite the growing popularity of empathy and compassion teaching in values education, and in social and emotional learning, we still know relatively little about supporting the development of empathic and compassionate dispositions. Kirschenbaum (1994, p. 33) notes that once we acknowledge the importance of teaching caring values, then it follows that we would want to teach them effectively and deliberately, not leaving the matter to chance, or occasional games, or the 'hidden curriculum'. 
Compassion, which is considered by some to be the most important of all moral virtues, contributes to one of nine core values covered in the National Framework for Values Education in Australian Schools (2005). Some effort has been made to describe how care and compassion might operate in this context through classroom resources (Freakley, Burgh, \& Tilt-MacSporran, 2008; Rowan, Gauld, Cole-Adams, \& Connolly, 2007), yet little is known about the different approaches to teaching compassion in school settings. Similarly, empathy is receiving growing attention within the field of social and emotional learning (SEL), in which it is conceptualised as one of the key constituents of emotional or social intelligence (Feshbach \& Feshbach, 2009). A range of empathy-focused literature describes the potential benefits of empathy for prosocial development, yet there remains a lack of detailed information about the ways in which empathy is fostered in education settings. Given the significance of empathy and compassion and their unique place within the continuum of caring outcomes, it is suggested that further exploration is required with respect to their application in education settings. In seeking to find out more about these values, I have explored two primary school programs, with the intention of providing insight into specific models of empathy and compassion teaching.

\subsection{Research questions}

The issues addressed through this research are broadly stated in the following two questions:

- Empathy and Compassion - How are empathy and compassion developed in these programs? Are the cognitive, affective and behavioural elements of empathy and compassion addressed through the programs, and if so, how?

- Broader Implications - What are some of the broader implications of these findings for the teaching of caring values? 


\subsection{Scope and approach of the study}

The two programs explored through this research were the Roots of Empathy, a SEL program focusing on empathy development, and the Voiceless Animal Clubs which comprised a network of extra-curricular clubs teaching compassion and respect for animals. There were obvious synergies across these programs which made dealing with them in a combined study attractive. Firstly, they both address caring values as a key focus for teaching and learning. Secondly, both programs sought to enhance children's empathy and compassion toward vulnerable others, namely babies and animals. This engaging approach to caring education potentially forms a powerful model of affective learning, due to the highly experiential ways in which these values are fostered, and the meaningful connections they draw upon.

In seeking to address the issue of the 'teachability' of empathy and compassion, I have employed a framework through which empathy and compassion have been explored, based on their cognitive, affective and behavioural components. The purpose in employing this framework is primarily to assist in the analysis of these two values, yet in the final chapter I also discuss the potential of explicitly addressing these three elements as 'signposts' within approaches to teaching empathy and compassion.

\section{The Case Studies}

A qualitative research approach was adopted in this study, and case study research methods have been employed as a means for exploring the two programs. The cases have been informed by interview data and secondary information. Interviews were carried out with four program 'instructors' from the ROE program, and five teachers who ran Animal Clubs in their school. Classroom observations in these settings were not practical given the time constraints for this project, and the need to conduct fieldwork 
across two states. The secondary sources consulted for this study include website information about the programs and, for the Roots of Empathy, program evaluations and two qualitative studies.

\subsection{Snapshot of findings}

In the conclusion to this thesis, the following findings have been addressed.

Relationships of caring for the vulnerable as a vehicle for empathic and compassionate understanding

The focus on babies and animals in these programs combines natural themes of caring, whilst absorbing children readily into another's experience. Moreover, there is potential in these settings to create, from these experiences, a more generalised empathy and compassion experience, which can contribute to the development of prosociality. This was a specific focus for the Roots of Empathy program, but not within the Animal Club.

Moreover, a central component of each of these programs involves situating caring education in the context of real settings in which babies or animals can be observed directly by children. The highly experiential aspect of the animal and baby visits allows for a very natural approach to values development and avoids values teaching based on an abstract character trait or watered down references to kindness.

\section{Compassionate advocacy}

Some attention is given in the final chapter to the notion of 'compassionate advocacy', and the fact that this provides a potentially useful model for achieving personal, social and global good. This study proposes the deliberate teaching of significant social and global issues in schools, using compassion as a lens for addressing issues of oppression, misfortune and suffering which impede the wellbeing of local and distant groups. It has 
been further suggested that there is utility in working alongside not-forprofit groups with respect to compassionate advocacy projects.

Empathy and compassion as cognitive, affective and behavioural constructs

It is argued that the teaching of compassion and empathy would benefit from specific attention to the cognitive, affective and behavioural elements which have been outlined as key features of these values in research literature. It is argued that these three elements can be addressed as signposts for teaching empathy and compassion. 


\subsection{Overview of the thesis}

\section{Chapter One: Introduction}

This first chapter outlines the study, provides the background to the issues analysed, and summarises the findings. It provides an overview of the study, and summarises the overall thesis arguments.

\section{Chapter Two: Literature Review}

Chapter two is the literature review, which is divided into two parts. Part one explores the teaching of caring values in education, focusing specifically on some key motivations and impediments within social, emotional and moral education in our schools. Part two explores empathy and compassion with a view to understanding their cognitive, affective and behavioural elements, and their potential applications in education settings.

\section{Chapter Three: Methodology}

Chapter three discusses the research methods and methodological approach used to guide this study. It describes the rationale for the choice of qualitative methodology and case study methods as well as practical approaches to data gathering and analysis.

\section{Chapter Four: The Case Studies}

Chapter four sets out the two case studies, drawing on interviews with those who ran the two programs, as well as secondary sources.

\section{Chapter Five: Cross-case similarities and differences}

Chapter five compares and analyses the cognitive, affective and behavioural approaches in each of the two programs, whilst highlighting some cross-case similarities and differences across the case studies. 


\section{Chapter Six: Final Implications and Conclusion}

Chapter six synthesises the overall arguments and findings and presents some broad cross-case implications of the research, together with some limitations of the study. It concludes by making some suggestions for future research, and offering some final reflections.

\subsection{Glossary of terms}

Some key terms have been used repeatedly in this study, and are described below.

\section{Animal Ethics}

Animal ethics refers to the study of how humans should treat other animals (Tulloch \& Verrinder, 2007).

\section{Humane Education}

There are two interpretations of the term humane education. In one sense, it commonly refers to the education of animal-related issues, and typically involves instructional approaches to teaching children kindness toward animals (Ascione, 1997). In its alternative and more generalised form, it has more recently come to encompasses not only teaching about animals, but also environmental education and human rights concerns (Selby, 1993). The meaning attributed to this term, in keeping with the focus in chapter four of this study, is the narrower interpretation which extends only to teaching about animals.

\section{Prosocial Behaviour}

Prosocial behaviour, as used here, refers to "voluntary actions that are intended to help or benefit another individual or group of individuals" (Eisenberg \& Mussen, 1989, p. 3). 


\section{Social Justice}

The interpretation of social justice used here is drawn from the description given by Reiss (2003, p. 160) which refers to the right treatment of others (the relational dimension) and the fair distribution of resources or opportunities (the distributional dimension). Social justice education has been and continues to be marked by a moral concern with those who have been 'othered' and marginalised through discriminatory relations that are seen as violent, both in symbolic and material terms (Todd, 2003).

\section{Social and emotional learning (SEL)}

Zins and Elias (2008, p. 234) describe SEL as "the capacity to recognise and manage emotions, solve problems effectively, and establish positive relationships with others". SEL learning reflects the fact that, as noted by Weare (2004, p. 96), "we have the ability to do far more than respond blindly to feelings: we can think about them, organise them, modulate them, moderate, and shape them through reflection and learning".

\section{Social, emotional and moral learning}

This phrase has been adopted as a term of convenience in this study, to cover the separate, (yet in some respects interlinked) fields of SEL learning described above, and values education.

\section{Values}

Values are taken here to be "the priorities which individuals and societies attach to certain beliefs, experiences, and objects, in deciding how they shall live and what they shall treasure" (Hill, 2008, p. 182). In this context, "values lie at the very centre of what we hold to be important principles to live by, or goals to work towards" (Fien, 2003, p. 12). 


\section{Caring and caring Values}

Whilst empathy and compassion are discussed and defined in detail in the following chapter, it is necessary to address what is meant by the term 'caring' and 'caring values' which have been referred to repeatedly throughout this research. In recognising the status of caring as an abstraction, a moral imperative, a fundamental value, and a philosophical ideal, it is evident that this concept resists strict interpretation (Hoffman, 2000). In seeking guidance on what the concept of caring entails in education any analysis would be incomplete without reference to $\mathrm{Nel}$ Noddings' $(1992 ; 1995)$ discussions of an ethic of caring in education, which builds on Carol Gilligan's (1993) work on caring and justice. Rather than defining caring in these settings, Noddings (1995) argues for a curriculum organised around 'centres of care' which can be pursued in many ways, including through curriculum, at the institutional and individual level. In seeking to describe how caring education is approached, this study has focused on only one aspect of Noddings' model of relational caring; and that is children as the 'one caring'. This recognises the limits when requiring reciprocity of caring, particularly with respect to non-human nature (Curtin, 2007). In seeking clarity about notions of caring, some direction is taken from Tronto (1993, p. 182) who talks of a conception of care which applies to humans, non-humans and the environment. She says care is "a reaching out to something other than the self" a process which is strongly associated with caring action.

Caring values, therefore, would be those which involve, in a metaphorical sense, some form of reaching out to others, though with specific respect to empathy and compassion, this would result from feelings of concern, and with the intention of seeking connection with others. Different commentators have made reference to an 'elite' set of values, whether they 
be labelled core values, ethical values or moral values (Lickona, Schaps, \& Lewis, 2007; Nucci, 2007; Haydon, 1997; Nielsen, 2005). Describing values in these terms seeks to differentiate them from generic values, which Jones (2009) points out are subjective in nature, and are not necessarily shared by everyone, or positive in impact. 


\section{CHAPTER TWO: REVIEW OF THE LITERATURE}

This review of the literature is divided into two sections. Firstly, it examines the place of caring values in contemporary education, including the varied motivations for addressing them in schools, and the specific personal, social and global benefits which they support. Attention is also given to concerns regarding the meaningful uptake of values teaching in schools due to the academic preoccupation.

The second part of this review briefly outlines some current applications of these values in education settings, and goes on to look at literature which describes these values as a synthesis of cognitive, affective and behavioural components.

\subsection{Part One - Teaching caring in our schools}

Almost twenty years ago, Alfie Kohn (1991) wrote in his essay on "Caring Kids: The Role of Schools", that the active encouragement of prosocial values and behaviour played little part in contemporary classrooms at that time. He attributes this omission to two factors, namely either a lack of interest in the idea of educating caring values and prosocial skills, or resistance to the idea of using schools in particular for this purpose. These aspects, which are referred to here as the 'motivation' and 'mandate' to teach values are addressed in turn in the following discussion.

Issues of motivation

The motivation to teach caring values in our schools would appear to derive from two strands of thought: on one hand, there is reference to a number of personal, social and global benefits which this education potentially supports. On the other hand, we are faced with what various sources 
describe as a societal and global 'crisis', with the result that many countries are beginning to pit values education against "dark forces" (Lovat et. al., 2009 , p. 107). The discussion below looks at both of these factors (opportunity and crisis), as important motivators across a range of affective learning fields.

Opportunity in values learning

The following discussion briefly addresses some of the personal, social and global benefits of addressing values learning in schools. Whilst this learning covers a range of activities and aims, some overarching motivations are offered below. Some effort has been made, where appropriate, to address some specific benefits of developing empathy and compassion in students.

There are a number of personally-derived benefits which may eventuate in values teaching settings. Firstly, we might deduce that this type of learning has the potential to contribute to more personally fulfilling lives for students which have meaning, joy, and satisfaction (Kirschenbaum, 1994; Schuitema, 2007). We may also see benefit in the fact that fostering social, emotional and moral learning can have significance for our sense of hope in the world. Areglado (2001) for example, notes that if we work to make our world a kinder, gentler, and safer place, we can improve the quality of life for many people. Conversely, the more selfish behaviour we experience in the world, the more threatening the world can become (Blizek, 1999). Some caring values may make us more 'open' in our thinking and accepting of different perspectives. Empathy, for example, decreases the likelihood that our values "will rigidify and become self-defeating through denying or excluding the external world" (Kirschenbaum, 1977, p. 11). This recognises that an ability to understand others, combined with a willingness to take their perspective, may increase receptivity to a broad range of perspectives. An absence of empathy, on the other hand, has been associated with delinquency, 
sociopathy and other criminal activity (Goleman, 1996; Kohn, 1990), with the result that some treatment programs include empathy development as a critical aspect for addressing antisocial behaviours, such as bullying and criminal offending (Gordon, 2007; Varkera, et al., 2008).

Secondly, there also appear to be a number of socially-oriented benefits in undertaking values learning. It is sound logic to assume that negative outcomes for individuals will also have negative repercussions for the productivity and wellbeing of a society (Thornberg, Hoffman, \& Remeika, 1991). Conversely, by enhancing the social, emotional and moral development of students, moral education contributes to the quality of society (Kirschenbaum, 1994; Schuitema, et al., 2007). Moreover, when the implicit modelling and explicit teaching of values is embraced by schools, this may have an enhancing effect on quality teaching, as well as positive implications for school relationships and ambience (Lovat et al., 2009). Indeed, De Roche and Williams (1998) point out that character education creates an environment designed to enhance the effectiveness of teaching and learning, suggesting that values teaching may positively impact academic outcomes.

Some of the more caring values, including empathy and compassion are linked with improved interpersonal functioning and prosocial action. Moreno and Klute (2008, p. 613) state that regardless of which of the several existing definitions of empathy is used, "it is agreed that empathy is a critical part of a broader moral sense that leads generally to harmonious functioning between individuals on a day-to-day basis...". Compassion has been labelled 'the social emotion' (Nussbaum, 2001) and like empathy, is considered to be a critical concept for working across differences and dissolving social and class barriers. 
There is a third element which provides further motivation for addressing the teaching of values, and this is termed here as the 'global' imperative. Concern about global issues has grown stronger in recent years, and can be linked in part to fears that our 'global village' is replete with threats that have the capacity to harm us all (Campbell, 2001). In this setting, we may perceive a large portion of humanity now living in one interconnected world (Slote, 2007; Whang and Nash, 2005; Epstein \& Elias, 1996). Environmental degradation is a particular concern within this dialogue (Hill, 2001) as well as war, oppression, poverty, uncontrolled population growth, and food, water and energy shortages (Noddings, 2004; Ozinga, 1999). In these settings, there is potential to support the development of more socially just local and global communities, through addressing values that assist in bringing us into closer alignment with distant others. Slote (2007) argues that given the evolving 'global village', it may be realistic to envision people having genuine empathic concern for distant groups and nations. In recent years the 'reach' of empathy and compassion have been expanded to include ways of relating to non-human animals and nature (Fien, 2003; Tulloch \& Verrinder, 2007).

Obviously, the benefits outlined above are not guaranteed outcomes from values learning, nor will they come about unless accompanied by sound approaches to fostering values. As Nielsen notes (2005) whichever core values are selected, we may, only succeed if our values education is based on certain pedagogical principles. Toward this end, some recent efforts have been aimed at exploring literature and practices across different settings (Schuitema, 2007; Thornberg, 2008; Okore, 2007), and exploring good practice in values learning (DEEWR, 2008).

Issues of crisis

The issue of crisis is one that emerges repeatedly in the varied literature relating to social, emotional and moral learning. Indeed, it is hard to 
overlook concerns regarding what is perceived to be a moral crisis facing our society (De Roche \& Williams, 1998; Kenan, 2009; Mitchell, 2004; Wringe, 2006). These concerns are typically focused on the increasingly negative story revealed through media and social indicators on crime, antisocial behaviour, neglectful parenting practices and poor social and emotional functioning. Youth, in particular, are a core focus within this discourse (Danaher, et al., 2008; Kay, 1975; Lumpkin, 2008; Vriens, 2000), lending credibility to claims that in contemporary settings young people today suffer from "too much emptiness and too much fullness - empty of love, meaning, purpose and something larger than themselves", and "glutted on sensationalism, stuff and speed" (Kessler, 2004, p. 61). There is no 'silver bullet' which will address the varied challenges which face today's young people. The problems they face are typically the result of a complex interplay of social and dispositional factors, including poverty, lack of family guidance and support, negative peer pressure and the adoption of misguided coping strategies (Thornberg, et al., 1991; Kessler, 2004).

\section{The mandate to teach caring values}

Whilst some of the problems stated above are complex and not necessarily within the direct area of influence of the school, there is reason to believe that the schooling system can and should make a substantial contribution to supporting the personal and social development of young people. In negotiating the form of this contribution, it becomes important to address the extent to which children's home life should also attend to developing the capacity for caring and positive social interaction which all children need. Whilst acknowledging that the bulk of social, emotional and moral learning takes place outside of school settings, there appear to be recurrent concerns that the home life of many children does not address social and moral development in sufficient ways (Kay, 1975; Kohn, 1991). Assuming 
this to be the case, supporting the prosocial development of students becomes both a parental and a public responsibility (Campbell, 2001; De Roche \& Williams, 1998; Gordon, 2007; Soren, 2001).

The Melbourne Declaration on Educational Goals for Young People (MCEETYA, 2008) states that young people should develop values and attributes such as honesty, resilience, empathy and respect for others, and should also have a sense of optimism about their lives and the future. Within this setting, the intellectual, physical, social, emotional, moral, spiritual and aesthetic development of young Australians is an important consideration for schools. These sentiments highlight the responsibility which all schools face, in supporting the social, emotional and moral development of young people. 


\section{Teaching social, emotional and moral learning in schools}

In recent years, there has been a growth in the number of programs which specifically aim to support the social, emotional and moral development of students. Within the field of values teaching, there has been a significant boost in recent years in the form of the National Framework for Values Education in Australian Schools (2005). This investment by the Australian Government has resulted from a commitment to values teaching as a policy priority in Australia (Toomey, 2006).

Furthermore, the increasing number of social, emotional and moral programs in schools, would suggest there is growing acceptance of the role this learning plays in the development of well rounded individuals, and in shaping environments which are conducive to learning. A large number of social and emotional learning programs are available to educators, giving a clear indication that we believe these skills should be taught in schools (Cohen, 2001; Epstein \& Elias, 1996,).

Despite these inroads into legitimating social, emotional and moral learning in recent years, it appears that there is a consistent challenge to the meaningful uptake of this teaching in schools, due to what is perceived as an over-emphasis on academic learning and measurable outcomes. Within this state of affairs, which is termed here the 'academic preoccupation', many schools hesitate to do anything that might detract from their focus on increasing academic performance (Benninga, Berkowitz, Kuehn, \& Smith, 2006). This preoccupation has been the source of concern across social and emotional learning, as well as values education (Burgess, 2005; De Roche \& Williams, 1998; De Souza, 2005; Downey \& Kelly, 1978; Epstein \& Elias, 1996; Kenan, 2009; Stewart, 2007).

In seeking to address this focus on the academic elements of schooling, it is useful to address some recurrent themes regarding the cause of the 
academic preoccupation. Firstly, it is important to acknowledge current education realities in which "teachers understandably feel under pressure to focus on the delivery of content and on equipping students with the knowledge to pass exams" (Harris, 2008, p. 368). In this setting, teachers may be somewhat at the whim of curriculum developers as the practice role of the teacher becomes oriented toward the language of "competencies and techniques" (De Roche, 1998, p.x).

Secondly, values teaching itself may be seen by teachers as 'tricky territory' (Kohn, 1991; Shaw, 2007). The openness of values debates, in which clinching proof of a position is often hard to pin down, easily leads to the view that such studies are 'soft' or 'vague' (Hill, 1991), or alternatively that they seek little more than to produce 'well-behaved' students, or promote conformity through shared values (Winton, 2008). It appears to be the case that caring values or virtuous traits are particularly liable to misuse in this way. Mitchell $(2004$, p. 3) notes that 'lists of values' have their limitations, and may be "no more than shopping bags of worthy sentiments, unless some good reasons are provided, at both a global and personal level, for adopting them". In accepting that producing 'well-behaved' students is a concern for many teachers, there is merit in approaches to values teaching which require more of children than simply 'following the rules' (Joseph \& Efron, 2005).

The issue of homogeneity is an important one, bringing with it a need to acknowledge the differing ideas across schools and in society (Haydon, 1997; Johnston, 2006). Yet there are arguably 'shared' values, or virtues, which resonate across different communities, cultures and global settings. Some commentators support the idea that certain shared values, moral values, or core ethical values, should be attended to in schools (Lickona, 
Schaps, \& Lewis, 2007; Nucci, 2007; Haydon, 1997; Mowry, 2007; Nielsen, 2005).

\section{An exploration of empathy and compassion}

It is the position of this study that certain 'caring' values should be focused on, and routinely addressed in schools. To further argue this point, in the following section, I look closely at two values, empathy and compassion, which have been offered as having particular significance within the continuum of caring values. Empathy and compassion were chosen as a focus in this research because the process of coming to know the internal state of another and respond appropriately is of "enormous importance for our life together" (Batson, 2009, p. 11). In support of these two values, I have looked at the possibilities for their development in education settings, and in the section which follows, some attention is given to the potential applications of empathy and compassion in education settings. Secondly, empathy and compassion are addressed in more detail, with particular consideration given to their cognitive, affective and behavioural properties.

\subsection{Part Two - Empathy and compassion}

Compassion and empathy have historically embodied what are considered to be some of the best elements of humanity. It is this "concern for the rest of the group" which serves as the cement of our society (Campbell, 2001). Given these observations, it is not surprising that in recent years, there has been growing interest in the potential of empathy and compassion across different education fields, primarily social and emotional learning and values education (Burgess, 2005; Cotton, 2001; Feshbach \& Feshbach, 2009). Before analysing these two values, it is necessary to address briefly the reason for approaching them as distinct constructs. Whilst in some contexts empathy and compassion are treated as identical (Cavanagh, 1995), they also differ in important ways. Most notably, compassion maintains a 
preoccupation with suffering and sadness, and a stronger imperative toward action than empathy. The cognitive composition of these two values may also differ given that empathy 'overdoes' the work of compassion: "It does so by supposing to enter into the other's suffering, rather than expose oneself to the other's suffering" (Tudor, 2001, p. 79). Indeed, empathy would seem to focus more strongly on the process of deliberately engaging with the thoughts and feelings of others, whilst compassion can be achieved through the seemingly simpler process of apprehending suffering. These differences are further elucidated below.

\subsection{Teaching empathy and compassion}

Exploring issues of 'teachability' is a critical step in taking values teaching beyond a 'nice idea' and creating insight into the many and varied way in which this can be achieved. However, before entering into this analysis, it is important to acknowledge that the 'educability' of empathy and compassion has been questioned by a small number of sources. Schertz (2007), for example notes that although empathy has been promoted by a variety of educational theorists for many years, the concept itself is fraught with ambiguity, and questions regarding its educability remain salient. Martin (2005) argues the importance of authentic opportunities to gain self-other perspectives, and voices doubt about engineered efforts at empathy development:

Perspectives and their exchange do not come about by abstract imaginings of others' experiences, minds, or worlds that result from adopting particular sorts of introspective or empathic strategies, nor do we come biologically pre-equipped with selves inclined to such strategic imaginings. Rather, it is primarily through our worldly activity with others that we come to know ourselves, others, and our world at all (p. 250). 
There is support for the notion that empathy should be situated in realworld contexts, "not just in our imaginations or in linguistic constructions of the world" (Teich, 1994). Yet there are equally those who consider that empathic and compassionate dispositions can be shaped through deliberate teaching. Whether through 'skills' such as perspective taking, or infused as values within curriculum-based learning, empathy and compassion teaching and learning approaches reveal wide-ranging potential for these two values in education settings.

In accepting for the purposes of this study that empathy and compassion can and should be deliberately developed in school settings, it is important to address how this might be achieved. Below, some current approaches to teaching empathy and compassion are addressed briefly, as revealed in the limited range of accounts and resources discussing these values in education settings.

\section{Empathy}

Feshbach and Feshbach (2009, p. 89) acknowledge that although the ontogenetic pattern of empathic development is unresolved, it is now generally accepted that empathy can be learned and therefore that empathy can be taught and trained. Empathy teaching has been discussed in the context of literature (Kehret, 2001), art (Phillips, 2003), co-operative learning (Teich, 1994), role playing, the study of famous empathic people and music (Levine, 2005; Burgess, 2005). Empathy has been addressed in values learning (Freakley, et al., 2008; Rice, 1995) and is an increasingly popular concept within the broad field of social and emotional learning, where it comprises a key component of emotional or social intelligence (Feshbach \& Feshbach, 2009; Zins \& Elias, 2008). A range of social and emotional learning programs include empathy development in their aims, such as the Learning to Care Curriculum (Feshbach, Feshbach, Fauvre, \& 
Ballard-Campbell, 1984), Second Step, the Citizen Curriculum, the PEACE Curriculum (Salmon, 2003), REACH Beyond Tolerance (Hollingsworth, 2003) and the Root of Empathy (Gordon, 2007). In these settings, empathy can be considered as an interpersonal skill, which can be learnt and fostered toward peers, as a means for increasing prosociality and overcoming bullying (Gordon, 2007). Despite the interest in empathy, the literature addressing detailed applications of this value within classroom settings is relatively limited. Most teachers have limited specific in-service training to teach children empathy skills (Burgess, 2005). With respect to empathy outcomes, Feshbach and Fesbach (2009) observe that it remains for systematic research and analysis to determine which empathy interventions and which components are most effective.

\section{Compassion}

Some effort has been made to understand approaches to teaching compassion across different fields including medicine (Burack, Irby, Carline, Root, \& Larson, 1999), psychology and social work (Pickard, 2003). Generally, however, there is little information detailing how compassion might be taught in different settings (Pence, 1983). In education, compassion has particular significance within values education settings. Ruiz and Vallejos (1999, p. 5), for example, propose compassion as "a new model for moral education" and note that to educate for compassion is to educate for a moral life. Compassion has also gained attention as contributing to one of nine core values included in the National Framework for Values Education in Australian Schools (2005). Whilst little is known about how this value has been interpreted across different settings, the Values Education Good Practice Schools Project: Stage 1 Report (DEST, 2006) suggests that 'care and compassion' has been applied by a small number of schools to service learning, charitable projects, and peer mediation activities. Compassion has 
been fostered as a character trait or as a 'virtue' (Kirschenbaum, 1994), and in other settings, it has also been associated with literature, journal writing and history (Freakley, et al., 2008; Rowan, et al., 2007; Trentecoste, 2006; Zeece, 2009). Alternatively, there is potential for compassion to be employed toward particular issues, such as in teaching historical issues (Trentecoste, 2006) or with respect to animals (Weil, 2004; Bekoff, 2008). Indeed, the field of humane education is often associated with compassion, with a core aim in these settings being the development of compassionate attitudes toward animals, the environment and human rights concerns.

\section{Summary}

In deciding that empathy and compassion have unique and important potential, we would want to find engaging, sound approaches to supporting the development of these values in schools. Yet a gap has been identified in literature regarding detailed insight into the ways these values are taught.

In the next section, some inisght is sought into the specific composition of empathy and compassion with a view to understanding these values better. In gaining clarity around how these values, virtues or emotions as they are variably interpreted, can be taught, some insight may be gained into those aspects which should be addressed in teaching. To structure this discussion, empathy and compassion are examined below as a synthesis of cognitive, affective and behavioural elements.

\subsection{Empathy}

\section{Defining Empathy}

As an English word, 'empathy' was coined in 1909 by Edward Titchener as a translation of the German Einfuhlung, which roughly means 'to feel one's way into' or to 'enter in the feelings of another' (Tudor, 2001). The most familiar images of empathy are those of walking in another's shoes (Todd, 
2003) or putting oneself in another's skin (Teich, 1994). However, despite the relative simplicity of these interpretations, the literature on empathy reveals this concept to be layered, and highly context-specific. This complexity is revealed through Batson's $(2009$, p. 8) account of the varying forms which can comprise empathy:

- Knowing another person's internal state, including his or her thoughts and feelings;

- Adopting the posture or matching the neural responses of an observed other;

- Coming to feel as another person feels;

- Intuiting or projecting oneself into another's situation;

- Imagining how another is thinking and feeling;

- Imagining how one would think and feel in the other's place;

- Feeling distress at witnessing another person's suffering; and

- Feeling for another person who is suffering.

Given the considerable potential for variation, it is not surprising that a recurrent theme in the empathy literature pertains to the definitional inconsistencies which serve to complicate discussions of this concept (Goldstein \& Michaels, 1985; Preston \& de Waal, 2002). The result of the varied theories and interpretations of empathy are not all necessarily comparable across different fields (Varkera, et al., 2008). For the purposes of this research, a definition of empathy has been adopted which recognises this concept as a combination of cognitive, affective and behavioural components. The definition here is that proposed by Caselman (2007, p. 6), namely "the ability to perceive and understand the inner experience of another and to express that understanding through a supportive response". 


\section{Cognitive Empathy}

Eisenberg and Strayer (1987, p. 168) note that although it is easy enough to state that everyone sees the world differently, such a concept is difficult to internalise and "repeated and ongoing effort is needed to see the world through the eyes of others and to understand situations from diverse points of view". In a cognitive sense, empathy is the ability to become aware of others' thinking and feeling states. It is often linked with the cognitive skill of perspective taking, which involves the comprehension of the thoughts and feelings of another person (Bierhoff, 2005; Oliner \& Oliner, 1995). In looking more closely at the process of perspective taking, Batson et al $(1997$, p. 751) offer two different components of this concept: imagining how you would perceive the situation (imagine self), or imagining how the other perceives the situation (imagine other). They argue that the latter evokes 'pure' empathy (evoking altruistic motivation), whilst the former invokes egoistic motivation due to experiences of personally-oriented distress . Perspective taking may be developed in stages, with young children being capable of basic perspective taking skills, which develop over time (Rice, 1995, p. 13). In keeping with this increasing empathic ability, cognitive maturing will lead to a capacity for more advanced perspective taking ability. Slote $(2007$, p. 15) notes that adolescents become aware of the existence of groups or classes of people and the common goals and interests that may unite them, and "this makes empathy with the plight, say, of the homeless or the challenged or various oppressed races, nations, or ethnicities possible and real for adolescents in a way that would not have been possible earlier in their lives".

Watson and Greenberg (2009) offer a complex conception of cognitive empathy that goes beyond perspective taking to also include abstract reasoning and cognitive flexibility as essential elements of the cognitive 
empathy process. Abstract reasoning requires that people be able to make interpretations and engage in higher-order reasoning about other people's perspectives, motivations, or intentions. Cognitive flexibility, on the other hand, is differentiated into spontaneous flexibility and reactive flexibility, as follows:

Spontaneous flexibility refers to an individual's verbal fluency or ability to quickly and easily generate ideas about another's cognitive and emotional state.

Reactive flexibility is the ability of individuals to shift attention back and forth, comparing and contrasting information about their own emotional and cognitive states and those of others in order to sort hypotheses and rapidly update working models of other people's emotional and cognitive states (p. 132).

Whilst Watson and Greenberg's conception of cognitive empathy, shows this aspect of empathy to be something more complex than simply putting oneself 'in the shoes' of another, there are few clues as to how abstract reasoning and cognitive flexibility skills might be developed. Whilst they note that natural disposition will dictate that some are better at these aspects than others, they also point out that both cognitive and affective empathy skills can be improved upon, from which we might deduce they can also be taught.

Affective Empathy

In its affective sense empathy refers to shared affect, or feeling what another feels (Gribble \& Oliver, 1973; Maxwell, 2006; Pfeifer \& Dapretto, 2009). Whilst some descriptions centre on the sharing of negative affect, namely sadness, others centre on the sharing of experience (Caselman, 2007) which presumably opens empathy up to a wider range emotions than compassion. 
Whilst most sources attribute empathy with shared affect, this is not invariably the case. Bierhoff $(2005$, p. 149) for example, suggests that empathy "does not necessarily require vicarious experiencing of the emotion of the other person" but simply requires the cognitive capacities of comprehension of the viewpoint of another person in order to understand the other persons state or condition. In this cognitively-oriented interpretation, an emotionless reaction to the empathic subject may still qualify as empathy, such as when someone experiences a positive reaction to the misfortune of others (Decety, Michalska, Akitsuki, \& Lahey, 2009). Nussbaum (2001, p. 202), who describes empathy as a 'mental ability', says it is both "fallible and morally neutral". She contrasts this to compassion which she describes as "more intense and suggestive of "a greater degree of suffering, both on the part of the afflicted person and on the part of the person having the emotion". Therefore, whilst most empathy literature attributes affect sharing as an essential part of empathy, this is not an essential requirement across all empathy literature.

\section{Behavioural Empathy}

Typically, empathy is recognised in the social psychology literature as a synthesis of cognitive and affective processes (Pfeifer \& Dapretto, 2009; Varkera, et al., 2008). However, when addressed in education contexts, empathy often carries expectations of empathic responding and behaviour, and this is the basis on which it is addressed here. Ruiz and Vallejos (1999) for example, note that affective training to encourage empathy must culminate in an affective reaction towards others and be translated through behaviour. Other conceptions of empathic action see it associated with 'prosocial action' and helping as well as 'displays of concern' for others (Caselman, 2007). 


\subsection{Compassion}

\section{Defining Compassion}

Wuthnow (1991, p. 283) observes that compassion is one of those things, like beauty and truth, that is simply an end worth pursuing in itself; "One should be compassionate naturally, instinctively, because it is good". Compassion is linked with religious tradition where it features in Christianity, Buddhism and Hinduism, and sometimes forms the hallmark of social missionary activity (Lampert, 2003; McGaghie, Mykto, Brown, \& Cameron, 2002). The etymology of the term compassion derives from the Latin verb pati (to suffer, to endure) and cum (with), to suffer alongside, to bear with. It is often interpreted as an emotion, together with an emotional response which generates activity and commitment: a desire to help (Rowan, et al., 2007). Other literature on compassion variably addresses it as a virtue (Carr, 1999) as well a motivational framework for altruistic behaviour (Bierhoff, 2005). Aristotle believed compassion has the following properties:

Let compassion be a sort of distress at a an apparent evil, destructive or distressing, which happens to someone who doesn't deserve it, and which one might expect to happen to oneself or someone close to one, and this when it appears near (Aristotle 1959, 2.81385 b 13-16 Quoted in Crisp, 2008, p. 234).

Generally speaking, compassion typically evokes sadness on behalf of the observer, however the complex cognitive processes attributed to the observer by Aristotle, and subsequently adapted by Nussbaum (2001), have been critiqued as excessively detailed, and self-centred (Crisp, 2008; Carr, 1999). For the purposes of this study, compassion is viewed as a mixture of cognitive, affective and behavioural components (Cavanagh, 1995; Sprecher \& Fehr, 2005). The definition of compassion used here is that borrowed by 
Ruiz and Vallejos (1999, p. 7) from Moliner's Dictionary, namely, "feelings of pity for the sufferings of others; the desire to alleviate, remedy or prevent such suffering".

\section{Cognitive Compassion}

Cognitive compassion has been described as an appreciation of suffering under which another labours (Carr, 1999). Exactly how this appreciation is arrived at is not settled across the different accounts of compassion. Cavanagh (1995) for example, treats cognitive compassion in much the same way as empathy, namely in terms of perceiving and comprehending another's psychological state (perspective taking). Tudor (2001, p. 79), on the other hand, denies that any attempt to 'see through the eyes' of the compassionate subject is necessary. In distinguishing empathy and compassion, he notes that empathy involves "a more active (if only imagined) projection of the self into the situation of the other" whereas the work of compassion involves a process of exposing oneself to the suffering, leaving a "respectful distance" to the other.

Friedland (1999, p. 35) says compassion can be triggered by any number of things ranging from "witnessing the effects of persistent chronic hunger to feeling the seriousness of a tune". The variable nature of compassion leads Crisp (2008, p. 234) to argue that compassion is highly contingent and lacks reason. He notes "Depending on what time I turn the radio on in the morning or which newspaper I read, I may be moved to help some mental health charity ... or someone who lives nearby who needs a life-saving operation". However, any concerns about the pervasiveness of compassion in society are not reflected in current realities, given what Cavanagh (1995) describes as the relative absence of compassion in modern society. Similarly, a generalised conception of compassion fails to acknowledge that individuals have internal beliefs and attitudes which make them "receptive or indifferent to the 'force' of the suffering" (Pence, 1983, p. 190). 


\section{Affective Compassion}

Feeling is an important component of compassion, as evidenced in Snow's description of compassion as a "relatively intense emotional response to the serious misfortune of another" (Snow, 1991, p. 197). It leads to a sympathetic reaction of distress on the part of the agent-the one who feels pity or compassion (Carr, 1999). Historically, compassion's sorrow is the target of many anti-compassion criticisms (Tudor, 2001). Many people are discomforted by the pain of others (Bierhoff, 2005; Decety, et al., 2009). Within Buddhist teachings, people have sought to reinterpret compassion's sorrow through fostering equanimity and lack of attachment to another's experience (Frakes, 2004). Others may actively avoid being placed in these emotionally demanding situations through the use of avoidance techniques (Shaw, Batson, \& Todd, 1994) and by limiting exposure to situations which prompt compassion and empathy (Hodges \& Klein, 2001). Admittedly, there are considerable sources of suffering in society, as indicated in the phenomenon of 'compassion fatigue' which is a common problem in the helping professions (Gillath, Shaver, \& Mikulincer, 2005). Cavanagh (1995, p. 318) states that whilst only negative emotions such as distress, are deemed appropriate targets for the compassion, "it can be just as detrimental to a relationship for partners to be incapable of sharing each other's happiness as to be unable to share each other's distress". Whilst not typical of other approaches toward compassion in the literature, he goes on to raise the possibility that happiness is a legitimate target-emotion as far as the affective component of compassion is concerned.

\section{Behavioural Compassion}

Action is an essential component in many interpretations of compassion, more so than empathy, leading to compassion being suggested as leverage for addressing relationships of inequality and oppression. Compassionate 
action can take many forms of helping, from benign giving, to political advocacy. Rowan, Gauld et al. (2007) note that in Australia today, displays of compassion are often associated with the provision of physical of financial support to those 'less fortunate' than ourselves. Other forms of compassionate action are more demanding. Lampert (2003) notes that compassion can lead to a critical view of reality and in many instances, also constitutes praxis for social change. Ruiz and Vallejos (1999, p. 7) regard compassion as "help, commitment and protest" which is founded on a feeling of responsibility toward others.

Compassion has been addressed with respect to its potential to alleviate or reinforce relationships of inequality. Whilst some may see it as highlighting inequality between the giver and receiver it is generally considered as an important tool for creating equity in the sense of "suffering with rather than having power over" (Garber, 2004; Whitebrook, 2002). Ruiz and Vallejos $(1999$, p. 7) are careful to point out that the 'other' person "is not a mere suffering object but a subject with a wounded, abused or frustrated dignity who demands a response". Whether the compassionate response contributes to perpetuating or alleviating inequality would presumably depend on the specific form of compassionate action and its potential to address the structural causes of misfortune or oppression.

\section{Summary}

To conclude, some attention has been focused on the potential of empathy and compassion, as well as their composition. This analysis reveals interpretations of the different elements comprising empathy and compassion to be the subject of small differences, reflecting varied interpretations and ideologies around the composition of these values.

In seeking to find out more about empathy and compassion, I examined some identifiable components within each of these values, and explored a loose structure through which empathy and compassion might be understood. There is little guidance as to how these elements might 
translate in education settings, though Cavanagh (1995) supports the use of these elements of cognition, affect and behaviour, as a 'map' for teaching compassion.

\subsection{Conclusion}

In summary, this review has addressed some key themes across the literature on values teaching, focusing initially on the potential motivations for teaching empathy and compassion. This part of the discussion reveals that whilst there may be a number of reasons for addressing caring values in schools, there is ongoing concern that the potential for social, emotional and moral development in schools is impeded by a narrow focus on academics.

With a view to gaining a deep understanding of empathy and compassion, the second part of this literature review explored the application of empathy and compassion in education settings. A gap has been identified with respect to a lack of information on the specific ways in which these values can be interpreted and taught in classroom settings. However, further insight has been sought through a close examination of interpretations of these values across different literature.

In following chapters, further clarity is sought through the specific examination of two different approaches to empathy and compassion teaching. Chapter Four explores empathy and compassion within the context of two primary school programs, and frames the discussion around some aspects of cognition, affect and behavior which have been raised in this chapter. Prior to laying out these case studies, the next chapter explains the methodological approach used to guide the collection and analysis of data, in light of the literature on qualitative and case study research approaches. 


\section{CHAPTER THREE: METHODOLOGICAL APPROACH AND STUDY DESIGN}

In this chapter I discuss the methodological approach and research methods used to guide this research. In particular, this chapter provides the rationale for the choice of qualitative methodology, and the methods which have guided the collection and analysis of data in this study.

\subsection{Qualitative research approach}

Qualitative research may be difficult to define because it is many things to many people (Denzin \& Lincoln, 1994) and carries a variety of conceptual associations (Freebody, 2003). In very general terms, it explores social phenomena (Wiersma, 2000) and is often focused on describing human experience (Lichtman, 2006). It can be contrasted to quantitative research in that it focuses on seeking insight rather than generating numerical data (Bell, 2005; Bogdan \& Biklen, 2003; Lichtman, 2006). Qualitative studies can draw on both inductive and deductive approaches. Inductive approaches allow the researcher to 'build' a theory, through inductive research strategy (Merriam, 1998). Wiersma (2000, p. 12) describes this inductive approach in similar terms, as "reasoning from the specific situation to a general conclusion".

There were a number of reasons why the present study was aligned to a qualitative research approach, the most obvious being the highly exploratory nature of the research topic and questions. Gillham (2000) notes that qualitative research methodology allows a researcher to investigate situations where little is known about what is there or what is going on, and to explore complexities that are beyond more controlled approaches. Furthermore, qualitative research relies heavily on the voice of individuals 
(Lichtman, 2006), making it suited to those studies which draw on interview data. It also allows for a small number of research participants if that is the aim of the researcher (Allen, 2004), and is driven by questions which ask why and how rather than what and how many (Lichtman, 2006). Bearing these factors in mind, the choice of qualitative research approach in this study was made with reference to the importance of achieving a "good fit" between a research question, and its methods (Punch, 2009).

\subsection{Case study within the qualitative paradigm}

The case study, which is one of the most popular methods of social science research aims to provide rich and detailed accounts through the in-depth study of a particular case or cases (Burton, 2000; Lichtman, 2006). Creswell (1998) describes case study as an exploration of a bounded system or a case

(or multiple cases) over time through in-depth data collection involving multiple sources of information.

Strengths and limitations of case study

Case study can provide insight into a single instance, making it a common method of choice for studying interventions and innovations (Lancy 1993). Simons (2009) outlines a number of strengths to case study approaches, including their flexibility and the ability to include a range of methods if that is the intention of the researcher.

There are also some common misconceptions and criticisms regarding case study. These include concerns that they are too subjective and lack rigour (Simons, 2009; Yin, 2009). Simons (2009) says that far from being a weakness, this element of subjectivity is an inherent part of case study. She joins other commentators in stating that subjectivity in research is not, in any event, avoidable by the researcher. Some further attention has been 
given to the issue of subjectivity in the later discussion on acknowledging and mediating researcher bias.

Another common misconception of case study is that all case studies seek generalisability. This assumption ignores the true purpose of case study which is to provide in-depth study of one or a few cases (Punch, 2009; Jones, 2006; Stake, 2000). Punch (2009) points out that generalisation will often not be the aim of the researcher, particularly with reference to those cases which are of intrinsic interest due to their uniqueness, importance or misunderstood nature. With respect to these cases, the researcher is usually concerned with the individual case and has little interest in the advance of science (Stake, 2000).

Despite the highly contextualised nature of many case studies, in some instances, generalisability will be possible. This includes those situations where an author creates abstract 'concepts' and 'propositions' as a result of the case, as opposed to purely descriptive accounts (Punch, 2009). To help the reader navigate issues of generalisability, Jones (2006) draws on Denscombe's (1998) suggestion that it is vital that a researcher includes sufficient details about how a case has been selected and how it compares with others in the class. Within this study, there was intrinsic interest in exploring the two programs in this study further. They were unique, relatively small in scale, and little is known about them in Australian education settings. Yet the case studies also have instrumental interest, because they were selected in order to offer insight into wider issues, namely empathy and compassion teaching, and relationships of caring. With this in mind, some broader implications are envisaged beyond the immediate settings explored through this study. 
Why case study?

One of the reasons I was drawn to the case study approach is because, as noted previously, it allows for the incorporation of secondary sources, in order to tell a rich and multi-layered story about a case (Gillham, 2000). Within the present study, information published about these two programs became an important means for understanding their specific techniques for teaching empathy and compassion.

Moreover, the motivation for this study has been to create an in-depth picture of empathy and compassion teaching across the programs, whilst also allowing for some cross-case analysis. Stake (2006) says that the real business of case study is particularisation, yet there is also potential for some comparative work, across multiple case studies, if this is the aim of the researcher.

\subsection{Project design and approach}

The following section further explores methodological issues in the context of explaining the way in which the study was conducted and interpreted. This discussion looks firstly at the methods for enlisting participants and gathering data, followed by a description of the way in which the data was grouped and analysed.

\subsection{Data collection}

Silverman (2006) observes that while it may be useful initially to explore different kinds of data, the researcher will need to establish the dataset with which they can most effectively work within the available timescale. Classroom observations might have been useful in this study, and could be a focus in further research, but they were not possible given time constraints for this study, and the fact that the fieldwork was carried out in two different states. Accordingly, the approach was to draw upon interviews 
with those who taught the programs, as well as some secondary information. For the Roots of Empathy program, this included information taken from the program website, publications by the program's founder, Mary Gordon, and two qualitative research projects carried out on the program. For the Animal Club, secondary information related primarily to the website material from archived records of the program's official site.

\subsection{Conducting the interviews}

The decision to undertake interviews was motivated by a desire to access a depth of experience across each of the two cases being studied. Six Perthbased interviews were carried out in the space of a six-day visit, and the remaining three interviews were conducted in Melbourne. Seven of the nine interviews were conducted face-to-face. The remaining two were via phone, due to one participant becoming unavailable during the week of Perthbased interviews, and another being situated in a regional school in Western Australia.

The interviews were semi-structured, allowing for more latitude of response than the structured interview (Opie \& Sikes, 2004). They proceeded along the lines of an informal discussion focusing on participants' experiences of teaching within the two programs. May $(1989$, p. 175) discusses the importance of adopting a flexible approach to questioning in interviews. She notes that an important challenge in qualitative research interviewing is maintaining enough flexibility to elicit individual stories which are likely to vary a great deal (at least at first glance), while gathering information with enough consistency "to allow for comparison between and among subjects". Bearing this in mind, I attempted to give teachers and instructors sufficient 'room' in the interviews, to discuss issues of personal significance and interest in the context of the programs. To provide some structure, a set of open questions were developed about the programs, which evolved slightly as the interviews progressed, to allow for the exploration of newly emerging themes. 


\subsection{The participants}

Roots of Empathy Interviewees

Purposive sampling was used to select participants in both programs due to a relatively limited pool of potential interviewees. For the Roots of Empathy (RoE) program, all of the potential participants were situated in Western Australia. Of the 17 schools involved in this trial which began in 2005, very few were running the program in 2008. During the recruitment process, some phone calls were made prior to sending out letters, in order to establish which schools were still actively implementing the RoE program. It became clear that only three of the schools contacted during this first round of enquiries were still active RoE schools, much fewer than originally anticipated. To make up the minimum number of four participants, I ended up making an exception for one teacher who had run the RoE program the year previously, and had hopes of continuing to do so the following year. She was also situated in a special education setting and I believed this would add a unique perspective to the interviews.

For this program, I decided to interview the program 'instructors', who were specifically trained to deliver the RoE program. It is instructors who were responsible for teaching RoE, giving classroom teachers an opportunity to observe, assist and even participate in aspects of the RoE classes. This decision to interview instructors was based on the assumption that they had the wealth of knowledge about the RoE curriculum, and were familiar with how it unfolded in classrooms.

\section{Animal Club Interviewees}

The Animal Club was an initiative run by Voiceless, a non-profit think tank dedicated to alleviating the suffering of animals in Australia. I located the participants through the Voiceless Animal Club website, which published updates from various clubs across Australia, most of which were based in 
primary schools. From the website, and with the permission of Voiceless, a list of schools was drawn of all the clubs operating in the Victoria and the Perth region, and these schools were contacted formally via letter of invitation. In total, five schools were contacted, and five teachers were interviewed across Victoria and Western Australia. The issue of whether there were any potential state differences was not directly relevant to this study or to my key research questions, and was therefore not pursued in the analysis.

\section{Recruiting Participants}

For both programs, the recruitment process was the same. A formal letter of invitation was sent to the school Principal, outlining the study, and inviting the participation of anyone who was involved in implementing RoE or Animal Club in the schools. The Principal was asked to indicate consent to the school's involvement by passing the information on to the relevant staff member. The participants would then fill out a consent form and mail it back to me. Each of the principals contacted for the study was willing to forward on the information, and in all cases, the teachers or instructors of these programs agreed to participate. This resulted in a total of four participants for the Roots of Empathy case study, and five for the Animal Club case study.

By way of background, some information is listed below regarding the location of each of the participants, along with their experience with respect to teaching RoE or animal issues.

Root of Empathy

\section{Liz, Formerly an early childhood teachers, now in school leadership}

School: Medium sized community school in metropolitan Perth

RoE Program Involvement: Not running it this year, hopes to resume next year 


\section{Anne, Teacher}

School: Small multicultural suburban school in Perth

RoE Program Involvement: Running the program with three classes - year one, year two and year four / five

\section{Pamela, Education Assistant}

School: Country school in Western Australia

RoE Program Involvement: Running the program with a single pre-primary / year one class

\section{Angela, Teacher}

School: Metropolitan primary school in Perth

RoE Program Involvement: Running the Program with a single pre-primary class

\section{Animal Club}

\section{Susan, Formerly a primary school teachers, now in school leadership}

School: Low socio-economic school in metropolitan Perth.

Experience teaching about animals: Has been running her animal club prior to affiliating with the Voiceless network. She has a history of involvement animal advocacy organisations.

\section{Stefanie, Teacher}

School: Medium sized school in northern metropolitan Melbourne Experience teaching about animals: Says she grew up loving animals and has developed a "passionate" interest in animal welfare issues in recent years.

Joanne, Teacher

School: Small school in eastern metropolitan Melbourne Experience teaching about animals: This is her first animal club, but she has a history of involvement with animal welfare organisations. 


\section{Maria, Teacher}

School: Medium sized school in south east Perth

Experience teaching about animals: Has a lifelong love of animals, however, this is her first animal club.

\section{Leanne, Teacher}

School: Suburban Perth-based school in high socio economic area

Experience teaching about animals: Has taught animal ethics for many years, including other school-based animal clubs.

\subsection{Ethics}

In the course of this research project, all efforts have been made to conform to expected standards of ethical conduct in research. At the commencement of this research, a formal application was made for ethics approval to the University of Melbourne in accordance with procedures for 'low risk' research projects. Approval was also gained prior to approaching schools, from the Victoria Department of Education and Early Childhood Development, and the Western Australian Department of Education and Training.

Measures were taken to ensure that, as much as possible, the identities of participants remained hidden. It was brought to participants' attention that there remained a possibility that they may be identified by those who were highly familiar with these programs. Participants accepted this risk and agreed to be involved. They were also informed that they were able to withdraw from the research project prior to the completion of data analysis.

Within this research project, a process was developed to guide the research, and ensure that all the appropriate ethical measures were addressed with participants, including the development of a script to ensure that interviewing protocols regarding consent and confidentiality were 
addressed. Data was also stored in keeping with official requirements for the storage of data by the University of Melbourne.

\subsection{Interpreting data}

Inductive and Deductive Approaches to generating themes

Within the analysis of qualitative data, themes can come both from the data (an inductive approach) and from the investigator's prior theoretical understanding of the phenomenon under study (an a priori approach) (Ryan \& Bernard, 2003). Both of these approaches were employed in the analysis of the case studies.

Apriori themes are identified in advance of research, and can come from "agreed on professional definitions found in literature reviews; from local, commonsense constructs; and from researchers' values, theoretical orientations, and personal experiences" (Ryan \& Bernard, 2003, p. 88). Prior to beginning this research, I developed some key areas of interest with respect to the two programs which contributed to the development of a framework for analysing empathy and compassion. Specifically, after addressing the literature on empathy and compassion, the decision was made to look at elements of cognition, affect and behaviour as a means to guide the analysis of empathy and compassion.

Within this framework, there was also room for the development of some unanticipated themes which emerged from the data. With respect to the process for identifying themes, in most cases these arise due to the existence of recurrent patterns and themes in the data (Ryan \& Bernard, 2003; Stake, 1995). In the present study, some themes emerged as a result of repetition within topics addressed by teachers and instructors, in the course of describing their programs. Most of the themes which are addressed in the case studies relate to common experiences of teaching the 
programs, and were drawn upon to build a picture of common practices in these settings. In the Animal Club, for example, there was no set curriculum, yet it became apparent that teachers had similar approaches to dealing with issues of navigating fact, sadness and compassionate action with children. Aside from attention to recurrent themes in data, Stake (1995) also allows for the possibility that significant meaning may be drawn from a single instance within data. In a few cases, reference was made to particular practices by a single participant, which have direct relevance for the discussions of cognition, affect and behaviour. Where appropriate, these comments have also been included in the case study, to highlight a specific point, or paint a picture of diverse practices.

Cross-case analysis

Some cross-case analysis is carried out in chapter five of this study. The method of analysis employed in the final chapter is to address in turn significant aspects across both of the programs, with reference to the themes which guided the case studies. Against the cross-case analysis, some attempt has also been made to preserve the distinctiveness of each case, through addressing their unique aspects as part of the overarching discussion. This helps avoid what Stake (2006, p. 39) describes as the possible "mangling" of the rationale of case study (exploring the unique vitality of each case) through cross-case analysis. Bearing this in mind, attempts have been made in the final chapter to address not only the similarities in the programs, but also the significant ways in which they differ.

\subsection{Limitations and challenges of the research}

Whilst the project offers key findings and outlines implications, the limitations and challenges facing this research also need to be acknowledged. 


\section{Acknowledging and mediating researcher influence}

There is much discussion in the methodological literature on the issue of researcher influence, indicating the fact that as reflective practitioners, we should try to reflect upon ways in which our own backgrounds and beliefs shape the research we undertake and the analyses we develop (Snape \& Spencer, 2004). Whilst this is not strictly a limitation, explicit attention should be given to how the researcher's influence is reflected across the research project. Different sources have addressed whether researcher 'neutrality' is possible or desirable within the research process. Whilst Rapley (2004) says there are a range of perspectives in regard to interviewer neutrality, there seems to be a general acceptance that neutrality is not possible when conducting research (Janesick, 2003; Strauss \& Corbin, 1998; Ritchie \& Lewis, 2004). Gillham (2000, p. 7) believes that a research investigation is not neutral; "it has its own dynamic and there will be effects (on individuals, on institutions) precisely because there is someone there asking questions, clarifying procedures, collecting data". Whilst 'neutrality' is not an achievable aim for a researcher, there are ways to manage, and make transparent, researcher influence in the research process. Acknowledging conceptual approaches explicitly is an important way to state one's position clearly. Early on, the qualitative researcher identifies his or her own biases and articulates the ideology or conceptual frame for the study (Janesick 2003).

Bearing in mind the need for researcher reflexivity, I tried to employ reflective processes during the research project, which identified the specific assumptions which would impact on the interpretation and findings within the study. In particular, at the start of this research, I have disclosed a strong personal belief in the need to teach caring values, particularly empathy and 
compassion, in schools. I have also attempted to undertake conscientious approaches to interpreting and discussing data, which reflect, as fairly and accurately as possible, the contributions which were made by participants in this study.

The inability to access classrooms and curriculum

With respect to the Roots of Empathy program, a major impediment to the study of empathy development in this setting has been the inaccessibility of the curriculum, given its copyrighted status. Where possible, some reference has been made to the techniques the program uses to support empathy and emotional literacy outcomes. However, the difficulty in accessing this information has constituted an ongoing challenge to the formulation of this case study. Furthermore, there was some difficulty in the ROE setting, with explicating empathy teaching, from the emotional literacy curriculum. It became clear after looking at the program in detail, that these aspects were highly interrelated. This is a factor which has been addressed in the study.

The lack of similar research

The lack of identical research has formed an ongoing challenge to this study due to an inability to locate this study within an existing body of empirical literature. Where possible, some secondary sources have been drawn upon, yet their direct applicability is limited by a lack of congruence with the specific issues being addressed here. This means that the questions, findings and implications in this study have been guided with reference to sources which are relevant only in a very general sense, therefore limiting the extent to which this study could be compared against insights from other comparable studies. 


\subsection{Summary}

This chapter has outlined the choice of research methodology, together with the specific processes which were followed in conducting this study. A rationale has been provided for the use of qualitative case study methods, as an appropriate technique for addressing the highly exploratory nature of this work. The limitations of this data are discussed with reference to researcher influence, and will be touched upon further in chapter six of this research, with respect to the scope, aim and limitations of the research. The next chapter lays out the two case studies, which explore practical application of highly specific forms of empathy and compassion teaching. 


\section{CHAPTER FOUR: THE CASE STUDIES}

The following chapter outlines two case studies based on the programs which were explored through this project. The approach in each case is twofold. Firstly, some background is provided on the programs, to lend some insight into the aims and specific techniques employed by teachers and instructors. Secondly, empathy and compassion are analysed through the programs, with respect to some of the cognitive, affective and behavioural features of these values which were outlined in chapter two.

The case studies have been informed primarily through interview data, collected through interviews with those who delivered the programs as well as secondary information.

\section{CASE STUDY ONE}

\subsection{The Animal Clubs}

\section{Teaching animal issues}

Societal concern for nonhuman animals, be it for their welfare or for their rights, has increased markedly over the past half-century (Balcombe, 1999). The issue of animal welfare is increasingly being seen as a topic of global significance, not just because of the intrinsic importance of these efforts for the animals themselves, but also because the way that we treat animals says much about our society (Garbarino, 2007). There are highly caring themes within teaching about animals (humane education) which bring it into close alignment with character development for children (Bierne \& Alagappan, 2007). Compassion and empathy feature regularly in the humane education literature (Kaufmann \& Fitchett, 1999; Thompson \& Gullone, 2003; Weil, 2004), with compassion, in particular, being described as a key for bettering both animal and human lives (Bekoff, 2008). 
The following case study looks at a specific type of humane education, in the form of animal clubs. Whilst the majority of humane education programs take place during class time, often in the form of one-off pet responsibility programs, animal clubs operate in an extra-curricular format. Typically run by a motivated teacher or students in a school, animal clubs have the advantage of embedding active approaches to educating about animals, across school settings in a way that is accessible to a range of students in schools. The specific initiative explored below is drawn from an animal club network which ran across a number of Australian schools between 2005 and 2008, and which was overseen by the not-for-profit group, Voiceless.

The Animal Club case study

The Voiceless Animal Club program was a relatively wide-ranging animal club initiative involving more than 1,000 school-aged children across Australia. This network of clubs focused on promoting compassion and respect for animals as an explicit aim. The following case study draws on the experiences of five classroom teachers who ran Animal Clubs in Victoria and Western Australia. The teachers referred to in this case study were all the 'leaders' of their Animal Clubs, having started the clubs themselves and assumed the primary responsibility for running them.

The issues

Within humane education teaching, there are a vast number of potential issues to explore alongside children (Pattnaik, 2004). Within the Animal Club initiative, the issues covered with children were chosen by teachers alongside their students and were also guided by the online information provided on the Animal Club website. Stefanie, one of the teachers, reflected on the large number of different issues which could be addressed with her club: 
...there are so many things to focus on from the harp seals in Canada to having hermit crabs in children's bedrooms. It's hard to know where to start and what to focus on to get the message across. But factory farming kills the most animals and is the biggest and cruellest industry at the moment.

This focus on factory farming issues was encouraged by Voiceless, which focused clubs' attention on a different factory farming issue every year. Other issues which were addressed included basic pet care, animal conservation, shelter animals, and wildlife and conservation issues. Information was obtained by teachers from different sources. Resources, factsheets and links to further information were provided to teachers via the Voiceless website, and teachers also used their own networks, resources and ideas to inform their teaching. Some of the more popular activities included watching documentaries, hosting guest speakers, creating art, crafts, and murals, fundraising, petitioning and presenting at school assemblies. Many activities were intended to promote positive feelings toward animals, given that the clubs were attended voluntarily, typically during school lunch times.

\section{Teachers and school communities}

Whilst this study does not seek to focus primarily on teachers' experiences across different club settings, it is important to note that a single teacher was typically the driving force in each of the clubs. All of the teachers spoken to for this study were invariably concerned for the welfare of animals, and were willing to assume the (often sole) responsibility of running these clubs in their schools. The need for motivation to run an animal club was something which was acknowledged by all teachers. Maria said "I know our workload is heavy but if you've got a passion for animals you'll pick up on it and you'll do it." She said she enjoyed offering her 
students a more meaningful way to connect with animal issues than she was able to enjoy as a child. Whilst the majority of teachers were able to access some form of school support (either in the form of helpers, or yard duty concessions), Stefanie ran her club on her own and using her personal time. She noted that "it does tax your time but that's something I'm willing to do". Whilst all of the teachers showed a commitment to animal welfare issues, some described this in stronger terms than others. Stefanie, for example, says that whereas she has grown up loving animals, in recent years she says she has "almost gone from animal lover to animal liberationist". Susan, on the other hand, says she hadn't thought of doing an animal club in any previous schools, “I haven't even been that interested in animals really but I've become known as the animal person in the school". She started her club before affiliating with the Voiceless network, and has gone on to create an ambitious club program, which features a number of regular whole-school activities.

\subsection{Compassion in the Animal Clubs}

The discussion of compassion which follows is framed around cognition, affect and behaviour as key themes for framing the exploration of compassion in this program. These three elements comprise Cavanagh's (1995) conception of compassion, and also features in Muldoon et al's (2009, p. 78) three dimensions of "nurturance toward animals", namely emotion (children's affect, feelings and emotional investment in animals), cognition (ideas and knowledge that children have about the object of nurturance, its needs and how to meet them) and behaviour (skills children have in nurturing others and the application of these skills).

Before exploring these three elements of cognition, affect and behaviour, there are two things which deserve mention. Firstly, whilst these three components serve as a useful framework for analysis, they are, in practice, 
highly interrelated. Secondly, the lens of compassion does not tell the entire story of the Animal Club program. A range of approaches, activities, and interpretations were developed by teachers in these programs and this case study does not attempt to represent all of them. This recognises the diversity of teacher practices which characterised teaching in these settings.

\subsection{Cognitive compassion}

Two aspects are addressed in this discussion of cognitive compassion, both of which have the potential to foster insight into the lived experience of others. The first is the exercise of understanding the experience of animals including animal theory of mind and sentience through perspective taking, and the second is the provision of information to children to help them understand the needs and experiences of animals (knowledge outcomes).

\section{Perspective taking}

Simply recognising that animals were individual, sentient beings was a step toward developing compassionate attitudes toward them. Indeed, the assumption that animals are conscious and capable of experiencing negative sensations and emotions is at the core of most people's concerns about animal welfare (Mendl \& Paul, 2004). Highly related to perspective taking is the notion of 'belief in animal mind' which attributes to animals, mental capacities such as intellect, the ability to reason, and feelings of emotion (Knight, 2004; Hills, 1995).

Within the teaching of factory farming issues, it was important to some of the teachers to convey to students that the animals in these settings were individuals. Stefanie's club decided to focus on factory farmed chickens, and an important outcome in this setting was for children to understand that each of these animals was a living creature: 
What l'd like to focus on is seeing animals as individuals not as a whole. So each chicken is a living feeling being. It's not just a whole heap of chickens in a barn.

She says she is planning a visit by an animal carer with some hens, so that children might have an opportunity to find out more about the different personalities some of these animals display. Leanne, on the other hand, says she has focused her club on the idea that animals have feelings too just like us:

We got them to really think about, you know, how would you feel if you were that animal you know, that they've got feelings too, and it's so exciting because kids really do think 'oh wow, yeah, I would feel really bad if that was me'.

The emotional experience of animals cannot be ascertained with certainty: "a certain amount of falseness is inevitable which is true even when empathising with other humans" (Hills, 1995, p. 141). However, with increasing knowledge about animal sentience and behaviour, animals' physical and psychological state can be inferred with growing confidence. Some species of animals show behaviour that has functional parallels with human conscious cognitive processing (Mendl \& Paul, 2004), and with respect to emotions, we know these exist in many species other than our own (Ascione, 2004).

Physically-oriented perspective taking also featured in Maria's club. They carried out an activity in which they imagined how physical confinement might feel for a factory raised layer hen. The children in her club used this as a way to get a better understanding of the size of cages hens are kept in, by sitting for a short time in an imaginary box. These elements of physical and psychological perspective taking can assist children to understand the potential for animals to suffer. 


\section{Knowledge outcomes}

Some teachers highlighted the need to take a 'balanced' approach to the resources provided to students. This was particularly important where issues were controversial or implied personal changes for students, such as vegetarianism. These aspects are discussed further in the context of behavioural change. Secondly, it was important to be realistic about the changes which could reasonably be expected given prevailing societal practices. For example, Stefanie said that her club understands that animals will continue to be killed for consumption: "That's not going to change soon. But we want them to be able to be the free range chickens, and be the pigs that have room to walk around and do what they need to do".

Teachers often watched documentaries with students, and this was a key means for finding out about factory farming issues. Maria explained how her club decided to view two different perspectives regarding egg production, and how this became a 'critical viewing' exercise for her club:

...so we watched a video from the egg corporation... it was factual, very nice video. And so then we actually talked about 'They've told us the truth', you know we spoke a lot about that 'but what's missing?' ...And then the next week we watched the one done by Voiceless which ... had all the same sort of information but had a bit more about the actual cruelty side of it.

\section{Animal incursions}

Significant learning also took place during incursions by animal carers, farm hobbyists and wildlife representatives. This included visits by pet carers with dogs, guinea pigs and farm animals, as well as more exotic pets which children didn't often have opportunities to make contact with. Susan's club, for example, invited a reptile carer to come and visit. She felt that 
opportunities like this help children learn more about animals and also assist in overcoming fears or misconceptions about them. She says "When she came out to this school, this woman with all her reptiles, all the kids had a go, you know feeling them and touching them. And I think it changes attitudes". Clubs also had visits from wildlife carers who discussed the plight of various wildlife species. They shared interesting facts about animals with children, and also educated children about the responsibilities of caring for endangered or injured animals.

\subsection{Affective compassion}

\section{Mediating sadness}

Some of the literature on compassion describes sadness as an inherent component of the compassion concept. Snow (1991, p. 196) for example, describes compassion as a "relatively intense emotional response to the serious misfortune of another". Some of the animal welfare literature recognises the presence of sadness when addressing issues of animal suffering. Hawthorne (2008) focuses on the notion of 'traumatic knowledge' and notes that activists are generally motivated by emotion: the love of animals, for example, or rage against companies practicing abuse. Ideally this emotion should be addressed directly given that children need acknowledgment and support of their feelings about harm to animals (Myers, 1998).

In the Animal Club settings, teachers were aware of the need to monitor the feelings of sympathy and sadness in reaction to descriptions of animal suffering. Susan, for example, notes that she takes a careful approach to how much she shows children:

I show them to certain levels where I think they're most suitable. I won't show them to everybody... I don't want to fill the kids with sadness or make it too heavy for them. 
She says she tries to focus on the positive side of things with her club. For example she sometimes shows the RSPCA Animal Rescue show to her club:

I record that every week and I often show it to kids and they'll get a bit sad about the plight of the animal but then they'll say 'but look what's happened... I'll have them look at the positive side of it ...

When dealing with smaller children, it appears that there is a particular need to monitor the type of information which is presented. Maria talked about censoring a video on seal hunting, noting she had to remove a minute out of that out "because the little year one's and little year two's can get quite upset quite easily".

Voiceless also provided some advice regarding appropriate content for children's viewing. Joanne says that during her unit on pigs, she went to the Voiceless website to check what she could show them "and I could only show them pigs on concrete, like, I didn't show them pigs in pain or distress". Aside from censoring videos in some places, Stefanie warns her students about the potentially upsetting nature of a particular program, noting of one viewing session: "I even said at the start "some of you may be in tears by the end, it depends how it affects you". She found the need to censor necessary, but frustrating at times:

And there's so many things I would love to show them but I can't. And that makes it hard to get the message across because with the chickens you want to show the gory details. I mean they have seen pictures but nothing like what I'd really like them to see.

Despite the need for caution with distressing images, there is acknowledgement too, that they can provide compassionate motivation. Jenni $(2005$, p. 2, p. 9) notes that visual images assist the development of 
empathic and helping dispositions toward animals by promoting vivid awareness of individual suffering. She notes that emotion is central to moral life, both as a manifestation of important virtues such as compassion, and as an indicator that something we are party to or witnessing is wrong. In this sense, emotion can be "an essential starting-point for moral thought."

\section{Creating emotional connections with animals}

Positive affect, evident in experiences of wonder and satisfaction, potentially helps strengthen emotional connections with animals, and heightens the likelihood that children would feel inclined to act in their interests. Moreover, incorporating positive affect into these programs potentially assists in balancing out feelings of sadness about the plight of animals.

Having fun was an important part of the clubs, particularly given their extracurricular nature. Maria said it was important that her club members enjoy the activities they carry out, and "It needs to be fun as well as educational". Like the other club leaders, she incorporates a wide range of activities in her club program, which included opportunities to feel good about animals.

Similarly, interacting with animals also presented opportunities to celebrate their 'cuteness', as with Joanne's club which had 'warm fuzzy' sessions where someone brings in their pet. Maria says she has a couple of autistic children in the club "and they just get so much out of being involved with the animals - associating with them and just touching them and cuddling them and feeling them".

Susan feels that direct interactions with animals appeals to children who might normally be considered the outcast of the school. She describes how one of the 'tough' boys in her school surprised everyone around him by doting on a kitten she often brought to the school from an abandoned litter: 
... instead of being out on the footy oval or wherever he usually hung out, he'd be with this kitten curled up in his arms. It was quite interesting... he was actually a kind, loving boy and he was allowed to show it through this kitten.

The specific dynamic between child and pet animal may be particularly engaging and accessible to children because of the position of vulnerability which some of these animals are placed in. Melson (2001) notes that pets, in particular, form a ubiquitous opportunity for practice in nurturing, which is accessible to both genders.

Intrinsic rewards from helping animals

When children have opportunities to offer tangible help to animals in need, there is reason to believe that this experience is motivating and empowering for them. Oliner and Oliner (1995) note that perhaps the most compelling way people internalise caring values is by associating them with joy. Teachers described the sense of accomplishment that students experienced as a result of seeing how their efforts had made a tangible difference to the lives of animals. Leanne, for example, talked about the high level of emotion which operated in the first Animal club she ran:

A couple of years ago ... it was just so exciting, it was humming. All the kids felt they were making a difference in the world... Sometimes I almost felt that it had been... this whole energy had lifted almost to a spiritual level.

Seeing the positive results of campaigning was an important reward for the clubs, who gifted goods or money from fundraising efforts to animal organisations. Maria's club even visited a shelter to see how their collected goods were being used: 
We went to the animal protection society which is one of the non-government volunteer organisations we help so we collect food and supplies for them. So we collect it up and we got, you know, a couple of great big huge rubbish bins of stuff and we took that. And the kids could see where their efforts had gone into, so they've seen all the cats and the dogs that were being looked after...

Joanne provided prizes to her club members to acknowledge the kind things they have done for animals:

I give prizes for rescues...I praise the kids a lot like 'hi five - here's a prize if you save a caterpillar' stuff like that. I just show fuzzy stuff sometimes because it's heart warming and we talk about 'does that make you feel good?'

Students also have the opportunity to share successes with assemblies, and those clubs with a higher profile also shared their activities through newsletters, and even through local media opportunities.

\subsection{Behavioural outcomes}

The Animal Club represents a particularly powerful form of compassionate education, which allowed compassion to be acted upon to help animals. This has been termed in later discussion as compassionate advocacy. In the discussion below, behavioural outlets for compassion are addressed in two respects; group action undertaken in the course of the club activities, and personal ethical changes which also potentially come about as a result of the issues addressed in the clubs. The latter is explored only through the comments of teachers, as the specific outcomes in these programs were not observed or measured in this study. 


\section{Advocating for animals}

Some clubs undertook to disseminate messages about animal welfare within the wider school and community. Some of these broader education activities included displays in the school library, presenting to other students at assemblies, whole-school animal visits, and holding fundraising drives in schools. In this way, some clubs were seeking to be agents for values change outside of their immediate club settings.

These activities were intended to teach students about the different ways that they could advocate for animal welfare issues, as well as giving them the confidence and skills to perhaps continue these efforts in the future. Fundraising was a particularly popular way of helping animals, with many clubs making goods, and then selling them to raise money for animal organisations. Whereas all of the clubs undertook fundraising at some point in their activities, a few of the clubs engaged in active protest, through writing and sending letters of protest about topical issues such as whaling or sealing. Susan says that she even undertook a letter writing activity which eventually turned into a whole school exercise:

I asked the teachers if they could all go back to their classrooms and have the kids write letters or draw pictures in the case of the little ones ... they all went back to the classrooms and did it, yeah. They're pretty supportive.

Aside from opportunities to enact compassion as a group, the clubs also provide students with options for making personal changes with respect to personal ethical choices. This was an issue which required some care. In guiding behavioural change for students, teachers had to be careful regarding changes which impact children and their families directly such as ethical shopping choices and dietary habits. The need for care when dealing with the attitudinal and behavioural repercussions of newly formed values is 
clear, particularly when dealing with contentious issues or when addressing personal change for students.

Teachers stopped short of dictating what children's personal ethical choices should consist of. Maria says "...we try to get across our messages in a subtle way without forcing issues on the kids." Using the purchase of free range eggs as an example, she notes "The message is you want the kids to look at starting to buy free range eggs but you've got to get that message across without saying 'go home and tell your parents this is what you want'. Joanne notes, however, that at the end of the day, you don't know what students say when they get home. She says she has to be careful:

I had some grade one girls last year and whatever I said they took it home to their parents. And they were beside themselves if they thought I meant that they couldn't eat this or that. And I was never that full on with them. And they'd say to me things like "My mum gets Coles meat, is that cruelty free?" And I said, that Coles meat is fine, cause I was thinking that poor lady...

Teachers in these settings noted that some students showed stronger ethical leanings than others when it came to animal welfare issues. Most of the clubs seemed to have some older students who were particularly dedicated. Stefanie notes that there are probably around twelve kids who are really the dedicated ones in her club. Joanne, on the other hand, says there is one grade six boy who occasionally queries her personal values positions and teaching approaches with respect to animals; "he gets stuck into me because we're not looking at this and we're not looking at that, and how come you're not a vegetarian and that sort of stuff".

The issue of role modelling was raised by Leanne. She acknowledges the influential role that she potentially plays in influencing students' values in the Animal Club settings. Her comments reflected the belief that some 
students were quick to take messages on board, and this was something that she remained mindful of:

... so the way I can really get kids on side is a two edged sword because kids can get really excited, they can really take on board what I'm saying... sometimes it can be a huge clash of values for the parents and some parents may really resent you, or they may even feel that they're losing control of their kids.

She says she had difficulties with one particular parent who was unhappy that her child had become vegetarian as a result of her experiences in the club. She, like the other teachers I interviewed did not advise her students to adopt vegetarianism, though this was presumably a possibility within the exploration of factory farming issues. As a result of some of the backlash she has received from this incident, Leanne says she has decided not to teach anything 'controversial', as she is wary of complaints from parents. Joanne too mentioned some minor complaints regarding practical aspects of her club, including whether her activities constituted an infringement of school fundraising policy. However, she says most of the parents were supportive, and reported that two parents in particular regularly donate time and resources to her club. The other three teachers in this study reported no negative feedback from parents.

Investing in a more compassionate future

The development of future advocates for animals seemed to be one important motivator for teaching in the clubs. There appeared to be a feeling by a few of the teachers, that encouraging advocacy at this stage of children's lives could amount to an investment in more humane futures. Leanne reflects on the influence her club might have on those students who attend: 
The reason I'm doing it at this, the grass roots level, I guess I think children are the future, they are the people that are going to grow into adults and they are going to make choices about policy, you know, about the environment, about everything. And if you can ... reach them and put that little seed of compassion in them, our world has got the capability of being a different place...

Joanne hopes her club might have helped her club members develop more compassionate dispositions:

What we do helps the kids to know that there are things out there that are just a bit cruel and it would be good if 'when you grow up, why don't you try and do something about it' that sort of thing.

Aside from advocacy and future change, some of the teachers also sought to inculcate simple habits of kindness in students across their school. In these settings, small gestures were important, such as ensuring they don't hurt small creatures. Susan says of the students in her school that "our kids here don't step on any insect they see or any of that sort of thing, if they see a gecko or a spider or that sort of thing, we carefully carry it out and let it go". Joanne also saw this as important in her club:

Even if it just helps like one kid not to pull the wings off something in the yard, I'm happy. Because you still get so much of that and I'm like 'why'. So if any of that happens and I'm on yard duty, it's like these kids ... running around trying to find me.

Revisiting the aims of humane education

In arguing the importance of the social and global benefits of humane education, it is important to revisit the dual purposes of this learning. Firstly, 
on one level, these programs seek to address the welfare of animals - an endeavour which typically drives efforts in this area. Secondly, some humane education programs can contribute to the development of more compassionate individuals, who are compassionately-inclined not just toward animals, but also toward humans. Bierne and Alagappan (2007) point out, this latter element is a secondary, though still important aim within the context of this teaching. It may be the case that this connection with more generalised prosociality, will prove instrumental in securing the future of humane education as a regular feature in classroom teaching. The links between this field and human-directed prosociality has not been addressed in this study, but it is increasingly the subject of empiricallyfocused research in humane education (Faver, 2010).

Moreover, for humane education programs to make the greatest impact, they would benefit from becoming part of the mandated school curriculum. There are a number of sources who highlight the ease with which these issues can be incorporated into school curricula (Pattnaik, 2004; Selby, 1993; Weil; 2004; Tulloch and Verrinder, 2007). Yet animal clubs too, would seem to have their place. It appears teachers were able to engage in varied, engaging and action-focused approaches in these settings. One might also speculate that the ongoing presence of the clubs has the potential to embed learning more thoroughly within school environments, than one-off programs or finite curriculum projects. This is evident from the ways in which some teachers in the more active clubs were able to share their club campaigns with the larger school community, and embed their message more widely through assemblies and school events.

\subsection{Prologue}

Since conducting these interviews, Voiceless has announced the end of its Animal Club initiative, which officially ran until the end of 2008. Though it 
remains to be seen how many of these teachers will continue teaching issues of compassion and respect toward animals, the high level of commitment shown in these Animal Clubs is encouraging. Moreover, there is reason to hope that the compassionate efforts that these teachers made over the course of their clubs, will continue to influence not only the children they taught, but also other teaching professionals who have engaged with the Animal Club experience through Voiceless' website. 


\section{CASE STUDY TWO}

\subsection{The Roots of Empathy}

Children, babies and empathy

Whilst the idea of a baby and mother in the classrooms might seem incongruous, a small number of programs have drawn on the caring themes of infancy in an effort to develop the personal and prosocial abilities of children. The mother and baby bond is a particularly powerful relationship, and has been described by Mary Gordon (2007, p. 52), founder of the Roots of Empathy program, as a powerful dyad representing "the most influential, indelible and life shaping relationship ever". It is not hard to understand why a baby makes such an engaging 'teacher' given the unregulated display of emotions which characterise infant behaviour. Yet the unprecedented physical and emotional growth of babies also allows for a fascinating study of human physical, social and psychological development.

Infancy is a particularly apt focus within social and emotional learning, where the baby's emotional and social development can be drawn upon to teach emotional literacy themes. Some programs which have incorporated baby visits into social and emotional learning curricula include Education for Parenting (Heath, 1995), Baby Matterz (The Learning Partnership), and the Roots of Empathy (Gordon, 2003). The Roots of Empathy (RoE) is the best known of this range of programs. Based in Canada, this program has been piloted in the United States, Japan, New Zealand, and the Isle of Man, and was also trialled in two states in Australia from the beginning of 2005.

The Roots of Empathy case study

The following case study relates to the Roots of Empathy trial in Western Australia, which took place in 17 schools and 22 classrooms. It is based on conversations with four instructors who took part in the program trial, and 
has also been informed by two empirical studies by Cain (2007) and Bailey (2005). Cain's Western Australian-based study focused on interviews with four instructors and four hosting teachers, and examined the effect RoE has on teachers, children, the classroom and the broader community. Bailey's qualitative study was conducted with five RoE hosting teachers, who taught within a single school division in Canada. Both studies focus on the perceived effectiveness of the program as an emotional literacy intervention. Furthermore, a number of references to the techniques in this program are taken from publications about the RoE program by the program's founder, Mary Gordon. In particular, the descriptions of class exercises have been made with reference to many of Gordon's publications, due to the copyrighted nature of the program's curriculum.

The program

The Roots of Empathy builds on infancy as an experience that is relevant to all children, and which carries with it naturally occurring themes of caring. In between the three-weekly half hour visits by the RoE baby and parent, the class follows a detailed emotional literacy curriculum, with empathy development at its core. RoE is identified as an anti-bullying program by the program's Canadian developers. This focus on prosocial behaviour development is likely to have been instrumental in the decision to trial the RoE program in Western Australia in 2005. The program was funded as part of a $\$ 64.5$ million Behaviour Management and Discipline strategy and was trialled in 17 schools and 22 classrooms throughout Western Australia.

\section{The outcomes}

RoE has an overarching mission to build caring, peaceful, and civil societies through the development of empathy in children and adults. Within this mission, there exist five goals: to foster the development of empathy; develop emotional literacy skills; to reduce bullying, aggression and 
violence, and promote children's prosocial behaviour; to increase knowledge about human development, learning and infant safety; and to prepare students for responsible citizenship and responsive parenting.

The way the program operated

A family or single parent and their 2-4 month old infant form the core of the RoE program. During the baby visits, which occur nine times throughout the 27 week curriculum, students observe the baby, ask questions and listen to the parent and instructor discuss aspects of the baby's temperament and physical development. The visits are intended to be a concrete experience: “... students can pack the diaper bag, unfold a diaper, offer a toy, play with the baby, sing to the baby and ask the parent questions" (Bailey, 2005, p. 59). Children also learn to respond appropriately to what the baby is trying to 'tell them' through his or her behaviour. The program literature describes a typical baby visit:

During a typical Roots of Empathy family visit, the baby, parent and Roots of Empathy Instructor gather on a special blanket on the classroom floor. Students sit in a circle around the blanket and are taken through guided observations of the baby (Roots of Empathy, 2004, p. 121).

An instructor visits the class on a weekly basis to deliver the program to the specifications of the 639 page Roots of Empathy curriculum. During this time, the classroom teacher is able to observe, assist and participate during ROE classes, and also plays an important role in informally embedding the empathy and emotional literacy learning outside of mandated RoE time.

\section{Engaging affective learning}

Of the four RoE instructors who were spoken to for this study, three were classroom teachers, and one was an education assistant. All of them had put 
forward an expression of interest to be involved in the 2005 RoE Western Australian trial, and had participated in a four-day training program in order to become acquainted with the detailed curriculum. The teaching was tightly scripted, as noted by one of the instructors, Liz "we're told that you must say it and do it exactly as the program is." Generally this aspect of the curriculum was found to be helpful, though Liz mentioned she has to "adapt and change and scaffold" sometimes for some of the special needs children she teaches. Angela felt the terminology was specific, and in some cases "a bit heavy". For example, she notes the focus on there being "no safe amount of alcohol" and no cigarettes during pregnancy may raise questions for children whose family life doesn't reflect this reality. Generally, however, all instructors had very positive attitudes about the RoE program. They talked favourably about the engaging nature of the curriculum, the natural and effortless way in which the infancy theme integrates into the emotional literacy and empathy teaching, and the meaningful connections the children develop with 'their' baby. Anne, for example, commented that the program is delivered in a very practical and simple way. She says "It couldn't be more simple than a mother and a baby going into a classroom... the delivery of the program is so natural ..." Angela believed the natural themes in the program contrasts it with other values curricula:

The Roots of Empathy program is lovely because nothing about it feels contrived. Because you've actually got a connection with the baby ...you've got your main teaching area right there, umm, so everything feels very natural rather than "Right, today we are going to be talking about jealousy, who can tell me about jealousy..."

It became obvious from instructors comments that children form a real bond with the baby in their class, and get to know him or her well over the 
course of the 27 week program. Liz says "I've had quite a few parents who have said the children come home so excited, talking about 'their' baby, 'my' baby sort of thing". She also suggests that the bond that forms between the children and the baby is enduring in some cases. She spoke of one ROE baby which is still recognised by children three years on from the ROE program:

And that baby is now a little toddler who walks around the school and the children, even though they are about three years older, will still go up and greet him as their baby. And, yeah, so there's lots of lovely things like that.

All of the instructors confirmed that students engaged strongly in the baby visits. Pamela, says the visits are highly anticipated by her class: "They always talk about 'oh when Hamish comes to visit' and how they felt, and how it makes them feel happy and warm". Angela agrees there are a lot of "warm fuzzies" which come with this part of the program, with children saying "'when it smiled at me, it made me happy', that kind of thing".

Program Reach

In respect to the practical implementation of the program, there was potential to extend RoE as a school-wide initiative given that the curriculum is tailored to three different year groupings. Yet instructors were typically limited in the number of classes they could run, given that there was only a single instructor in each school and that instructors had other teaching responsibilities aside from RoE. Some of the teachers commented that it would be advantageous to be able to train more teachers to deliver the program. However the small scale of the Western Australian trial made this whole-school potential difficult to achieve, particularly given that there were no Australian-based trainers to deliver training to potential recruits. 


\section{Academic elements}

The Roots of Empathy addresses a number of different academic subjects, through the cross-curricula nature of the activities. Anne says "That's really the richness of it - you're looking at literacy, you're looking at art, you're looking at maths - measuring the baby, weighing the baby. It's so complete". The academic focus of the curriculum would seem to make the program more attractive to educators, as Gordon (Roots of Empathy, 2009) comments:

In the Roots of Empathy program we bring in many areas of curriculum which of course keeps teachers very happy because they can see their agenda is being addressed while we teach the counter-agenda of care.

For the purposes of the discussion which follows, the academic aspects of the Roots of Empathy program will not be addressed further. Rather, the focus of the following discussion is on the development of empathy through the program, and the extent to which the cognitive, affective and behavioural elements of empathy are addressed with children. As with the previous case study, the focus of this discussion is on one particular outcome sought through the program, and therefore does not represent the complete range of aims and techniques which RoE seeks to develop.

\subsection{Empathy development in the Roots of Empathy program}

It is important to highlight at this point that there are different empathic 'targets' in this program, with empathy development being fostered not just toward the baby, but also toward peers. Not surprisingly, the focus on

developing empathy for the baby and empathy for peers differs in key respects, and an effort has been made below to touch on some of the ways 
in which these approaches vary. Furthermore, because of the dual focus on empathy and emotional literacy within the RoE program, these aspects often overlap within the teaching approaches which are described below. Accordingly, whilst empathy is the core focus for this part of the discussion, selected elements of the emotional literacy curriculum are also addressed here, to the extent that they would appear to strengthen empathy development within the program.

Empathy as a skill and a value

Whilst not explicitly stated as such in the RoE program, empathy appears to be approached as both a 'skill' and a 'value' in these settings. The Roots of Empathy is primarily referred to as a social and emotional learning (SEL) program, focusing on emotional literacy development. However, it is also considered to be a character education program (Berkowitz \& Bier, 2006) and has a strong focus on instilling a 'moral voice' in children (Gordon, 2007). In this way, the program specifically attends to the moral development of students through the discussion of themes such as bullying and the importance of treating other students with respect. This dual conception of empathy is in keeping with the flexible nature of this concept, which sees it employed as a popular concept within values teaching, and social and emotional learning (Feshbach \& Feshbach, 2009; Ruiz \& Vallejos, 1999).

\subsection{Cognitive empathy}

Taking the Perspective of the Baby

In the RoE program, perspective taking is described as the cognitive component of empathy. To enhance perspective taking during the baby visits, observations of the baby are scaffolded by the questioning and direction of instructors who focus students' attention on what the baby 
might be feeling or thinking. Angela describes the way perspective taking can be focused, not just on the baby, but the mother too:

...being able to see with the baby, 'oh, he must feel so frustrated when he can't get his toy' and talking about that and 'what can we do' and 'how can we help' and all the sort of joyful things and frustrating things, and looking at mum's perspective of 'how do you think mum might feel if she hasn't slept, cause, you know, (the baby) has been sick tonight'.

Children in the ROE program don't just care about 'their' baby, they seek to understand it, including its physical needs, joys and frustrations. The Roots of Empathy students are encouraged to put themselves in the baby's place, "often getting down on the floor to see what the view of life is like from that perspective" (Bailey, 2005, p. 12).

\section{Peer-oriented perspective-taking}

Peer-directed concern and empathy is addressed through perspective taking activities, emotional literacy exercises, and literature. Students are asked to discuss hypothetical situations, such as imagining how they would feel in another's place or brainstorming empathic responses to different scenarios. For example, one exercise asks students to explore their feelings in relation to particular incidents, such as 'If your friend made a mistake in front of the class and everyone laughed how would your friend feel?' Gordon (2007, p. 157) says this scenario group work includes coming up with specific actions to take to intervene in an unfair situations. Often these take the form of 'what if' situations, which allow children to reveal emotions safely through creating a collective group response to questions such as 'How would a person feel if...?' or 'What could someone do to help them out?'

Angela says that she doesn't think children are often asked to speculate about others feelings: "I don't know that kids are always asked 'how do you 
think it might feel for someone else?'"'As a result of ROE, however, she feels her class last year became adept at perspective taking:

...they'd go off to the library and the library teacher would say, 'wow, when I read them a story, it's not so much the content they are concerned about, it's about how everyone feels'.

Anne says she finds opportunities to get students to imagine how their actions might influence others:

...and that's the essence of bringing it back, to me, from what the baby visit has done ... we try and use that, like, across the curriculum in terms of well, later, if you're hurting someone... 'how would you feel?'... think of that person ...and then stop yourself, you know, think of alternatives. So you know that's to me the strength of it, when the kids can start to apply it to other situations.

This practice is described in the empathy literature as induction, or drawing children's attention to the consequences of their actions on others to promote perspective taking and empathy (Hunt, 1990; Watson \& Benson, 2007).

\section{Linking thoughts and feelings and developing theory of mind}

As mentioned previously, there is substantial intersection between the development of empathy and emotional literacy. The ability to understand how another person is thinking and feeling is directly aided by an understanding of how emotion operates in our lives, and how it can be linked to thought processes. Whilst understanding the cause and effect relationship between feelings and events seems like a straight forward task, this can be challenging, particularly for younger children who have not fully developed abstract thinking ability. Gordon (2007) notes that children may 
not give thought to why they feel the way they do, but RoE explicitly helps them link cause and effect:

A further stage in emotional understanding occurs when children begin to connect ideas and feelings... In one of the exercises used in our program, children are given a picture of a girl who is sad and asked to reflect on reasons she might be feeling that way. Answers range from 'She's upset because other kids are teasing her' to 'She's sad because her dad just lost his job' (p. 119).

With respect to peer-focused perspective-taking, there is also a focus on temperament which potentially strengthens children's empathic understanding. For example, Gordon (2007, p. 60) notes that the strong focus on temperament in the program "hones empathic skills" as the child works out that, depending on the temperament, he and his classmates will approach situations differently and have different emotional reactions.

Indeed, one of the most basic precepts of perspective taking is the ability to understand that people think and feel differently based on their personality. This relates to the notion of 'theory of mind', which is the awareness that other people have a mental state, different from our own, which can explain their behaviour (Hooker, Verosky, Germine, Knight, \& D’Esposito, 2008). Self-knowledge (or intrapersonal understanding as it is referred to by some SEL commentators) can also aid empathy development, given that people who understand themselves "are less likely to believe that what they need is what others need as well" (Oliner, 1995, p. 35).

Gordon (2007, p. 84) notes that the discussion of temperament is entered into with tremendous enthusiasm by the children: "The context is exploratory and non-judgmental. They delight in identifying their own temperament traits and illustrate these traits by sharing stories of what they 
did as babies or toddlers". She says these discussions not only increase selfreflection and, consequently, self-knowledge, but also engender and understanding of their classmates in a very positive way.

\subsection{Affective empathy}

As noted in the literature on empathy development, affective empathy in its narrowest sense refers to a process of shared affect, or coming to feel as the other person feels (Varkera, et al., 2008). This interpretation is somewhat narrower than that given to affective empathy within the RoE program, which is "emotion" (Roots of Empathy, 2010). In addressing briefly whether the strict interpretation of affective empathy has been met in the program, it appears that the baby visits provide opportunities for shared affect and sympathy to be shown by students. Bailey (2005) states that empathic concern is fostered as children develop a relationship with the child and the parent, and personal distress may be felt as the children learn and witness the variety of positive and negative experiences that the baby has. With respect to peers, opportunities to share and empathise with others potentially arise through the discussion of hypothetical scenarios as well as within class discussions of the emotionally-focused literature which forms part of the program resources.

The emotional literacy curriculum also has potential to support affective empathy ability. Two aspects of the emotional literacy teaching in the program are touched on below, namely acquiring and using emotional vocabulary, and discussing emotions. Whilst to a certain extent, these skills might be viewed as learning about emotion rather than learning through it, it is suggested that this emotional literacy learning potentially helps strengthen empathy ability. 


\section{Acquiring and using emotional vocabulary}

As part of the RoE program, children are taught to understand emotions, including understanding what emotion is and the varying forms it takes. Secondly, they also learn to articulate emotion, and are given specific opportunities to practice describing their own emotional states and experiences, and those of others.

Acquiring an emotional vocabulary would seem to give children a greater ability to express how they feel. Angela says this new vocabulary enhances her students' emotional expression:

And they actually sound very sophisticated because they can say things like 'he felt very nervous' or 'he felt very anxious' and knowing that they have actually had enough engagement with that sort of concept that they do actually know what it means, I actually think that's really great for four and five and six yearolds.

Gordon (2007, p. 36) notes that the RoE program gives children permission to have a public discourse about emotion. This is not always something that students feel they can do, as Park (2003, p. 34) notes, young people can easily pick up that they do not have permission to speak about their feelings in school, and that it is therefore hardly surprising if they reply to questions about what they are feeling with an unrevealing "Okay" or "I don't know". To support understanding of emotions, students carry out activities such as reading stories which tap emotional literacy, such as fear, sadness, anger, shyness (Roots of Empathy, 2005), and also address a range of emotions with reference to the baby. They also have opportunities to practice emotional literacy language "in much the same way second language skills are taught in school" (Gordon, 2007, p. 124). This expression is encouraged through a series of staged exercises which include asking students to 
recount and draw a time they felt sad. The classroom teacher and Roots of Empathy instructor also share their own feelings and their memories of emotional experiences from their childhood.

Anne says the strongest message is it's ok to talk about emotion "that to me is what we need to be doing for all kids. You know, reassuring them it's ok to share your feelings". In order to safeguard the sharing of emotion, supportive learning environments are critical, and should focus on ensuring student learning occurs within a safe, caring atmosphere (Zins \& Elias, 2008). A few of the instructors commented on how personal the discussion becomes in the RoE classroom, as Anne notes, "They would talk about, you know, really personal circumstances where, you know "my little cousin died because my uncle shook the baby." Liz also says that "it's quite a powerful program - you can get disclosures. So you have to be very aware of that".

A couple of the instructors noted that the ability to express feeling states helped 'diffuse' feelings of negativity, so students were able to get on with doing their work. Anne, for example says that 'kids' emotional literacy levels drive them...we need to give them the space and the time and give them appropriate ways to show that emotion". She says the kids in her class are from challenging backgrounds, but their emotional literacy is developed enough that they will take time out:

But they will say "I need time out". So they will go quietly and they will just sit, and tell us what's happened. So instead of aggression, you know we still have that mind you ... but it's nowhere near as intense as it was at the beginning of the year. Because they know it's ok to say 'I'm not feeling good, I need time out' 


\section{Getting to know students better}

Opening up emotional and empathic dialogue through the emotional literacy curriculum appears to be a useful way for students, teachers and instructors to get to know each other better. This not only has potential for student-student relationships, but also has implications for student-teacher empathy levels. As noted by Angela;

This year in particular one of my boys comes across as a very confident little guy, and I've taught both his siblings. In actual fact he has become... he has shown himself to be quite insecure and quite anxious about lots of things so I don't think he would have revealed that if it hadn't been in a reasonably safe environment of Roots of Empathy.

Cain's (2007) research showed that teachers get to know their students better after observing them take part in RoE and that in some cases this had positive effects on their teaching. She notes that her participants believed there had been changes in the attitude and response of the classroom teachers as a result of the RoE program, which in some contexts were described as 'huge' and noted positively by staff and parents.

\section{Teacher uptake of the program}

Ensuring continuity of the ROE program outside of the scheduled ROE sessions was highlighted as an important factor by participants. Moreover, it is likely that these potential benefits for teachers and students will be influenced by the extent to which teachers engaged fully in the program. Whilst instructors felt that most teachers supported the program well, there were some who did not do so to the extent that instructors had hoped. Angela had one teacher who considered RoE sessions as 'dot time' and made no attempts to embed learning outside of the program: "...and because it didn't extend across to other areas it didn't have that continuity 
to it that I'd noticed the previous two years". Liz had a similar experience with two different RoE classes which showed very different levels of teacher uptake. She reflects "It's probably a personal judgment call on my behalf but my perception is that one teacher was far more along that line of emotional empathy and literacy". Given the vital role of the classroom teacher in cementing social and emotional skills in the classroom, the occasionally variable nature of teacher uptake in the program may be an impediment to the program's outcomes in a small number of cases.

\subsection{Behavioural empathy}

The behavioural outcomes referred to in this part of the discussion, include opportunities to 'enact' empathy in the RoE program, as well as the development of empathic attitudes and behaviours. The latter has not formed a core focus in this study given that outcomes were not explored here, however brief mention is made below to the specific findings of evaluations of the RoE program.

\section{Enacting caring}

Peer-directed methods for developing empathy included brainstorming ways of helping or supporting others, and through instilling a 'moral voice' in children through the caring expectations embodied in the RoE curriculum. The hypothetical nature of many of the activities in the programs (achieved primarily through brainstorming options for responding and acting in caring ways) reflects the challenge of creating authentic peer-related empathy experiences. Finding active ways for students to practice peer-related empathy, may depend on the ability of teachers and other school staff to explicitly encourage empathy to be practiced and acted upon outside of RoE settings. This recognises the importance within empathy development, of giving students opportunities to act prosocially toward peers, and commending them when this happens spontaneously (Caselman, 2007). 
With respect to the baby, children are required to respect the baby's physical space during the baby visits, however they do have some opportunities to interact from a distance through, for example, providing a toy. The children can also 'practice' acting in caring ways toward a lifelike baby doll, which forms part of the RoE resources. Whilst the potential for reciprocity in these settings is non-existent, most of the instructors felt this was an important vehicle through which children could enact caring. Anne observes of the doll, "You think to yourself how does a twelve year old show affection appropriately? Well, this was a tool through which they could do that". Anne, Liz and Pamela talked of the way in which the children's interactions with the doll became gentler and more caring as the program progressed. Pamela notes:

It was interesting at the beginning of the year ... we have dolls, and the kids were holding the dolls by the legs, by the arms, throwing them in the pram and all that sort of thing. Since we've actually been doing the Roots of Empathy program, they actually pick up the doll properly, like a proper baby, and they wrap it in the blanket and they carry it properly to support the head

The descriptions of interactions with the doll suggest that children often practice being 'mother' in these situations. Interestingly, these interactions also seemed to extend to boys. Liz says one of her classroom teachers was surprised to see boys consistently acting in caring ways toward the baby doll:

Year one boys don't normally go to the home corners. And if they went in and played with the dolls, in my experience, it was to put the doll in the oven or pull the hair out, you know, do something equally as gross as little boys tend to do ... whereas I observed these little boys going in and picking up these dolls and 
caring for them, and actually modelling all the things they'd actually seen the mother doing. ...this same little group of boys would be patting the baby, nursing, rocking them and they never ever left the home corner without putting the baby back down in the cot, in the right way ...Umm, they took the baby and kiss the baby goodnight and off they go. So it's just amazing.

The benefit in these settings would seem to be in enabling children to indulge in a tactile experience, in which they can mimic caring behaviour in a non-judgmental and caring context. The ability to appeal to boys is an important achievement in the program given that girls are generally deemed to be more empathic than boys (Litvak-Miller \& McDougall, 1997) and less likely to display prosocial behaviour in certain settings than girls (Eisenberg \& Mussen, 1989).

Peer-oriented empathic behaviour

Given that instructors were not present during the Roots of Empathy program, it was not expected that they would be able to comment on any behavioural changes to the RoE classes outside of the program. However, there have been a number of formal evaluations carried out on the program which report positively on RoE's ability to support peer-oriented prosocial development. An evaluation has been carried out on the Western Australian trial, from data collected in 2005. It found that the program "increased prosocial behaviour, reduced aggressive behaviour, and enhanced children's ability to manage their emotions positively" (Department of Education and Training, 2005).

\subsection{Prologue}

Despite positive evaluations of the RoE program, few of the original 18 Western Australian trial schools were still running the program at the time 
of this research being conducted. Funding constraints have made it difficult to develop the program (Parry, 2007) and Cain's (2007) research suggests that the lack of policy planning and support for the program's future was an issue for all of her participants. Despite this setback, the program still retains a strong base in Canada, and is continuing to implement trials in a number of different countries, with the most enduring overseas trial approaching its fourth year in New Zealand. 


\section{CHAPTER 5: CROSS-CASE SIMILARITIES AND DIFFERENCES}

Having laid out two case studies in the previous chapter, the following discussion explores different components of the case studies with reference to the research question and some cross-case themes emerging from the data. The core research questions guiding this study were:

- Empathy and Compassion - How are empathy and compassion developed in these programs? Are the cognitive, affective and behavioural elements of empathy and compassion addressed through the programs, and if so, how?

- Broader Implications - What are some of the broader implications of these findings for the teaching of caring values?

In exploring further the values of empathy and compassion, I have examined two specific programs in which they feature as core outcomes. The opportunity to look closely at the these programs reveals them to be highly oriented around caring values, and situated in settings which are meaningful and engaging for students. Both programs offer insights into the process whereby children come to understand others. Conversations with teachers and instructors have highlighted the authentic connections which were formed in these settings, and the caring actions and attitudes which characterise interactions with 'vulnerable others' in these programs.

\section{Empathy and compassion}

At the outset of this discussion, some clarification is needed regarding the different ways in which empathy and compassion have been approached in these programs. In one sense, both programs teach values explicitly: in RoE, empathy development is a core outcome and a focus for teaching and learning. In the Animal Clubs, on the other hand, compassion and respect for 
animals was the common (and explicit) theme uniting a diverse range of issues and learning experiences addressed by teachers. In these settings, 'compassion for animals' forms a highly specific form of compassion education.

There is some support for making values learning explicit rather than implicit. Through explicit approaches, values become ubiquitous, in that values 'teaching' and values 'learning' become part of the embedded consciousness within every school activity (DEEWR, 2008). Yet some sources also highlight the importance of addressing subject topics with a moral dimension and which students encounter as citizens in a democratic society (Schuitema, Dam et al. 2007). Obviously, these endeavours are not mutually exclusive, in that values can be taught through specific topics, whilst also being addressed explicitly with students. In adopting this approach, children are presented with opportunities to move beyond compassion as a value 'concept' and explicate some of the underlying attitudes and beliefs which feed into the formation of different values positions.

As previously noted, in the RoE program empathy is developed as a core aim of the program and is addressed through structured activities designed for this purpose. Some mention was made in this case study, of the way that empathy can be approached as a skill on one hand, and a caring value on the other. In this setting, empathy can be strengthened through the deliberate fostering of social skills, including perspective taking and emotional literacy. Yet empathy is also attributed with moral significance, with the result that children are expected not only to be able to understand others, but also to act in their interests. This dual interpretation means that empathy can be addressed within the context of values learning or within social and emotional (SEL) learning programs (or a combination of the two). 


\subsection{Empathy and compassion as cognitive, affective and behavioural concepts}

This part of the discussion centres on the techniques through which empathy and compassion development were supported through the two programs in this study. In order to guide the analysis, attention has been given to cognitive, affective and behavioural components of these values. In choosing this framework, I have been guided by literature on empathy and compassion that attribute specific processes of cognitive, affective and behavioural elements to these two values (Caselman, 2007; Cavanagh, 1995).

\subsection{Cognition}

Cognitive understanding with reference to empathy and compassion is taken to mean here the process of coming to understand the inner experience of the other in the case of empathy, and apprehending the suffering of another, in the case of compassion. Perspective taking, or inserting oneself into the experience of the other, is often considered to form the cognitive element of empathy (Bierhoff, 2005; Oliner \& Oliner, 1995). In compassion development, an apprehension of suffering will most likely be assisted through some understanding about the empathic or compassionate 'target', and the specific hardships they face. This understanding can be supplemented with reference to the provision of information (described here as 'knowledge outcomes'). These aspects of cognition are addressed further below.

Perspective taking and the RoE program

Perspective taking encourages students to immerse themselves in another's experience (Borowiec \& Langerock, 2002). Primarily a cognitive skill, it requires the ability to correctly infer what others are thinking and feeling 
(Oliner \& Oliner, 1995). In the RoE case study, perspective taking is most obviously cultivated with reference to observations of the baby, and also with reference to hypothetical scenarios relating to peers. In seeking to understand the baby, part of the 'skill' of perspective taking here is observational in the form of observing the baby's demeanour. However, perspective taking with reference to peers on the other hand, may be somewhat less visually apparent, and more obviously inclined toward state of mind, rather than visual display of emotion. In this setting, getting to know ourselves and others will help encourage empathy.

In the RoE program, the emotional literacy exercises allowed students to discuss feelings and experiences. A few of the instructors felt this aspect of the program helped them get to know the students well, and Cain's (2008) study suggests teachers' empathy for students increases as a result of the emotional literacy curriculum.

The aspects described so far would seem to go toward imagination (deliberately imagining another's experience) and familiarity (understanding the target of empathy, or his/her circumstances). Furthermore, in addressing how to teach the cognitive aspects of empathy, we might ask whether simply imagining what another is experiencing is enough, or whether there are supporting skills which strengthen children's understanding of others. In this program, there were additional elements of the emotional literacy curriculum which might enhance children's abilities to speculate about feelings. In particular, they learn about dispositional differences through the study of temperament, and they also have specific practice in drawing connections between thoughts and feelings. Through learning about some of these 'basics' of human nature, children are developing knowledge that assists not only in developing empathy, but which also facilitates daily social interaction. 


\section{Perspective taking and the Animal Club}

Nussbaum (2001, p. 333) states that we are much more likely to have compassion for the pain of animals if we are able to "reconstruct their experience of the bad things we do to them". In the Animal Club, perspective taking was practiced by a few of the teachers, through focusing with students on what it was like to be in the position of an animal. Aside from perspective taking as such, these efforts also potentially contribute to educating about belief in animal mind. Knight et al (2004) state that belief in animal mind is a term used for how we attribute to animals mental capacities such as intellect, the ability to reason, and even feelings of emotion. This understanding could be significant for children in the context of teaching compassion for animals, because it highlights the idea that animals are individual creatures ("not just a heap of chickens in a barn").

\section{Knowledge outcomes}

In both programs, children's understanding about animals and babies will be strengthened to some extent with reference to contextual information, about their lives, needs and capacities, and (in the case of animals) the specific hardships they face. This is termed here as 'knowledge outcomes'. Gaining this contextual insight is particularly pertinent within compassion development, reflecting cognitive compassion (as it is understood here) as a process of exposing oneself to sadness, rather than explicitly entering into the experience of another, as with empathy.

In the context of humane education, providing accurate information to students is important (Weil, 2004). In the Animal Clubs, some of this information was factually based, such as the documentaries and website information. Brief reference was made in the Animal Club case study to the intersection between fact and values which takes place in this teaching. In these settings, aside from a focus on the factual, there is clear support for 
practices which are humane to animals, and which reflect values of compassion and respect.

In this context, there may be benefit in having activities and resources provided via the Animal Club website, so teachers can feel guided and supported in the values, and content they present to children. All of the teachers reported referring to the website for resources, including seeking guidance about what could and couldn't be shown to children.

Fact also intersects with values in the RoE program, as evidenced in one instructor's comment about the 'zero tolerance' approach in the RoE curriculum to alcohol and smoking in pregnancy, and how this might not be reflected in all children's family experience. In these settings where fact and values intersect, there is merit where addressing strong values positions, in doing so explicitly and transparently. A number of sources caution approaches which leave values to the hidden curriculum. Veugelers (2000, p. 41), for example states that whilst teachers cannot make all of the hidden curriculum explicit "that is no excuse for not analysing the values teachers find important for their students and how teachers work with these values in their educational practices".

In both the Animal Club settings, and in the Roots of Empathy program, the values being represented were made explicit, in that they were cited as key objectives of both programs. However, the specific ways in which these values were translated were guided with assistance from the RoE curriculum on the one hand, and the Animal Club website on the other. Moreover, as previously noted, exploring a range of values positions may be a good learning opportunity for students. Soley (1996), for example, states that teaching 'about' values is less difficult than 'teaching values', and highlights the importance of allowing students to gain a deeper understanding of others' values as well as their own. Whilst not wishing to address in detail 
the long history of values clarification techniques, and their place within the field of values teaching, it is important to note that understanding diverse values should be an important outcome, particularly with respect to topical social issues. It is further suggested that this undertaking (exploration of diverse values) should not be inconsistent with taking a caring perspective or position toward complex issues.

\subsection{Affect}

Emotion may make learning more poignant and therefore more memorable for students (Stewart, 2007). Emotion has been addressed as a key ingredient in moral behaviour (Downey \& Kelly, 1978), and an aid to moral deliberation (Pizarro, 2000). Emotion features explicitly within interpretations of empathy and compassion, making it an essential element to address within the teaching of these two values.

\section{Empathy and emotion}

Emotion in empathy is described as affect-sharing or feeling the same as another feels (Gribble \& Oliver, 1973; Underwood, 2009). In the RoE program, there is evidence that some opportunities for shared affect exist. Bailey (2005) comments that students have opportunities to feel empathic distress alongside the baby during the RoE baby visits. Yet even these experiences might more accurately be described as sympathy rather than empathy, something which Underwood (2009) differentiates in terms of feeling for (sympathy) as opposed to feeling with (empathy). With respect to peers, there are ample opportunities to imagine what another is feeling (and potentially feel the same as them) through hypothetical scenarios, and through discussions of the program's assigned literature. Some of the success of these experiences may lie in teachers' ability to make these imaginary encounters real for children. 


\section{Emotional literacy learning}

The emotional literacy teaching in the RoE program opens the classroom up to authentic interactions in which children draw, write and talk about their own feelings and experiences. Instructors talked about how children open up in these situations, but they also mentioned how learning basic emotional 'skills' aided this expression, such as knowledge of emotions and emotional vocabulary, and the ability to attribute emotions to thoughts. A distinction was made by me in the RoE case study between teaching 'through' emotion, and teaching 'about' emotion. Whilst strictly speaking, the latter approach is more a cognitive skill in nature than affective, it was queried whether these skills might potentially strengthen affective empathy ability. Learning emotional vocabulary, for example, aids emotional understanding and expression, and potentially normalises the presence of emotion-based dialogue in the classroom. In the Roots of Empathy program, students learn and use emotional vocabulary "in much the same way as a second language" (Gordon, 2007, p. 124).

Another emotional literacy skill which has not been addressed in this study, but which has strong links in some literature to caring capacity, is emotional regulation. Emotion regulation seems to have a particularly important role in social interaction, given that individuals who can regulate their emotions are more likely to experience empathy and to interact in morally desirable ways with others (Decety \& Lamm, 2009). A few of the instructors made reference to the importance of being able to 'clear the air' by enabling students to express their negative feelings or take time out when needed. They felt this aspect of the RoE program was beneficial for the creation of productive learning environments.

Whilst it has not been addressed in depth here, deliberate approaches to teaching through and about feelings requires a sensitive approach by 
teachers. Caring environments are important in SEL programs (Zins, et al., 2007; Greenhalgh, 1994), particularly in the RoE program where children discuss personal experiences and feelings. Instructors in these settings had some training in emotional literacy teaching, in recognition of the fact that emotional literacy learning in particular, requires skilled educators (Brunker, 2007; Weare, 2004).

\section{Addressing sadness}

Within compassion, affect is often characterised as a feeling of sadness experienced by someone in the face of another's suffering (Tudor, 2001). In the Animal Club, the typical 'sadness' which characterises compassion is present in many aspects of teaching and learning, and is typically associated with knowledge about the plight of animals. A few of the teachers talked about not wanting to "fill students with sadness", and there was evidence of attempts to mediate sadness through censoring some of the more distressing information about animals. However, the potential for sadness to motivate compassion is an obvious reason to find workable, sensitive ways of supporting children with these feelings. Acknowledging and discussing emotion may be a useful technique here, as well as channelling sadness into positive action. Presumably, explicit acknowledgment of affect is an important part of accepting emotion, and validating of sadness as a normal and sometimes inevitable aspect of caring about animals. At the same time, there are obviously limits to the amount of suffering which children should be exposed to. To aid this judgment, Voiceless provided guidance on appropriate viewing for children, alternatively, teachers used their judgment on what was appropriate in each circumstance.

Cavanagh (1995) acknowledges that generally the compassion literature discusses only negative target-emotions with reference to compassion, yet he suggests that positive affect such as happiness could also constitute a 
legitimate emotion as far as this treatment of the subject is concerned. In the context of the Animal Clubs, positive emotions were also identified and discussed with reference to creating caring 'connections' with animals, thereby reinforcing compassionate feelings. These include the intrinsic rewards experienced from helping animals, and the 'warm fuzzy' experiences of interacting directly with them. Presumably, the creation of caring connections with animals strengthens children's feelings of caring for animals, and makes it more likely that they will act in their interests.

\subsection{Behaviour}

Some support has been given by some sources for the importance in values learning of providing a bridge between moral knowledge and moral action (Lumpkin, 2008; Nielsen, 2005; Kristjánsson, 2010). This focus on moral acting supports the notion that the facilitation of doing and feeling should be far superior to the facilitation of thinking on its own (Nielsen, 2005). It may even be the case that acting in accordance with personal values requires courage because in some cases it may require a person to "stand out from the crowd and be different" (Lumpkin, 2008, p. 49). Behaviour in these settings has been described here in two different ways: opportunities to enact empathetic and compassionate values during the course of the program, and the process of internalisation of values. Only brief attention has been given to this second point, reflecting the fact that neither the outcomes achieved in these programs nor their durability were able to be observed or measured in this study.

The Roots of Empathy

Within the context of empathy development, providing real situations to act empathically is important, and will include creating environments where empathic behaviour is expected and recognised when it happens spontaneously (Caselman, 2007). In the RoE program, children were given 
opportunities to act in empathic ways through the baby visits, and through the interactions with the classroom doll. They also have opportunities to 'brainstorm' forms or empathic action and prosocial behaviour during the baby visits and during group exercises which formed part of the emotional literacy curriculum. Ideally, opportunities to enact empathy would transfer through to learning which takes place outside of the RoE program. However, instructors suggested that the uptake of the program by teachers was occasionally less than hoped, meaning that a small number of them presumably failed to embed the programs outside of RoE sessions.

Despite this, the program did explicitly address moral motivation in the form of attempting to develop a 'moral voice' in children and through expectations of prosocial behaviour which were explicitly voiced through the curriculum material. Some evidence suggests that children are also assisted to develop empathic curiosity, through the practice of perspective taking, as evidenced through one instructor's comments that when students were read to by the school librarian, all they appeared to focus on was "how everyone was feeling". This recognises that whilst empathy has been associated with prosocial action, this element does not tell the whole story of empathy. Rather, it is in one sense a process of coming to understand others, which results primarily in insight, and which is then (ideally) followed by prosocial behaviour.

\section{Animal Club}

Compassion is accompanied by a desire for action (Ruiz \& Vallejos, 1999). The real strength of the Animal Club program in achieving its compassionate aims appeared to be the ability for compassion to be 'acted upon' in these settings. Behavioural outlets for compassion were provided in a range of ways through undertaking group advocacy activities, such as education, campaigns, and fundraising efforts, and through the consideration of 
personal ethical choices. It is presumably the case that the extra-curricular nature of the clubs frees up teachers to address 'hands-on' approaches, to these issues, as opposed to the more curriculum-centred focus of classroom teaching.

Importance has been assigned to values teaching approaches which offer real opportunities to students to develop agency (DEEWR, 2008). In the Animal Clubs, there is evidence that students work as a community with teachers, to 'brainstorm' potential forms of action, and to decide on which forms of advocacy to undertake. These efforts represent a highly experiential form of learning and also provide tangible help to animals through fundraising efforts. In the following chapter, I explore further the notion of 'compassionate advocacy', drawing on this active approach to compassion as a means for addressing important social issues.

With respect to shaping children's personal attitudes and behaviours, some of the teachers also mentioned the more sensitive issue of addressing personal ethical choices with students. Some distinction here is offered between values and attitudes. Attitudes are beliefs that have been derived from a particular value and express a view about what should happen in particular situations (Fien, 2003). All of the teachers highlighted the importance of not telling students which specific behaviours they should undertake with respect to more contentious issues. This appeared to be particularly important with respect to factory farming issues or matters which implied personal change for students. With respect to these particular issues, teachers said they left students to decide on their own personal practices, yet in keeping with the value of compassion for animals, animalfriendly choices are discussed favourably over those which adversely impact the welfare of animals. 


\subsection{Summary}

To summarise, I have analysed some of the ways in which cognitive, affective and behavioural components of empathy and compassion have been addressed in these two programs. In the following chapter, some key findings and implications are identified, drawing on some of the points raised in this discussion. These address the utility of cognition, affect and behaviour as 'sign posts' for empathy and compassion teaching, as well as outlining some further potential implications which have arisen in this study. 


\section{CHAPTER 6: DISCUSSION AND IMPLICATIONS}

This chapter provides a synthesis of the main findings and arguments from across the study and outlines four key implications of these findings.

\subsection{Implications}

The implications which have been drawn from this study can be stated as follows:

1. It is important to situate empathy and compassion within meaningful settings, which provide experiential hands-on approaches

2. There is a benefit in exploring varied approaches to educating empathy and compassion, including efforts to address compassionate advocacy in schools

3. There is importance in attending to the cognitive, affective and behavioural elements of empathy and compassion in teaching these values

4. Teachers should be supported to address caring values such as empathy and compassion with their students

\section{The importance of situating empathy and compassion learning within} meaningful settings which provide experiential hands-on approaches

Two particular programs were explored in this research, both of which draw on children's relationships of caring for the vulnerable. To many people the relationships we have with children and animals may be considered ordinary, yet in these programs, babies and animals are the 'messengers' for empathy and compassion. It is their obviously engaging nature which draws children to them, a factor which is no doubt highlighted in the incongruous setting of a classroom. Lampert (2003, p. 178) argues that children, more so 
than adults, have the ability to enter into a conscious state of compassion and "this can be easily discerned in their compassionate attitude toward babies, puppies, and pain of others".

The way we treat both babies and animals says much about ourselves as a society, and efforts to relate to them in a caring way has great intrinsic merit. There are obvious benefits for animal welfare on one hand, and for the growth of positive parenting ability on the other, in pursuing these types of programs in schools. Yet there are also benefits for students in the form of the highly experiential approach these programs offer to compassion and empathy development. This is an experience with which many children would seem to connect, according to the teachers and instructors who were interviewed for this project. They mention the emotional investment the program elicits from children, and the special dynamic which emerges between the children and the baby, or animals. Associating opportunities to care about another with joy, may reinforce caring as a positive experience. Oliner and Oliner (1995) for example, support the idea that the most compelling way people internalise caring values is by associating them with joy. There is also obvious support for the idea that values education is much more effectively conveyed through contexts which are engaging and meaningful for students, as noted by Weare (2004, p. 96), "If we want learners to respond to an experience, to remember it and to change as a result of it, we need to make the learning personally compelling, emotionally deeply felt and, vividly real".

The highly experiential aspect of the animal and baby visits also allows for a very natural approach to fostering values and avoids values teaching based on an abstract character trait or hypothetical references to kindness. These programs situate caring education in the context of real situations where it can be modelled, observed, and practiced. These caring relationships are the 
cornerstone for prosocial learning and acting in these programs, yet it is also important to acknowledge that it takes knowledgeable, careful and skilled educators to develop an effective empathy or compassion-based curriculum based on these activities.

\section{Opportunities to enact caring}

Burgess (2005, p. 165) describes programs involving engaging with a baby and/or an animal as "hands-on" approaches to empathy development. Interacting with babies and animals was a central part of each of the programs. Whilst the 'incursions' or 'visits' by babies and animals operated as a small part of the programs, instructors and teachers in these programs commented on the importance of these experiences for pupils. Comments such as "they get so much out of it (interacting with animals)" or "they just want to cuddle that doll" show how children engage in these opportunities. It was obviously important to the educators that children have a chance to show they care through tactile experiences. This provides another form of expression through which children can show themselves to be caring individuals, in a way that might not be otherwise possible or acceptable in classroom settings. These experiences would also seem to be something which is accessible to boys, as reflected in some of the teachers' and instructors' comments that boys can unselfconsciously cuddle the baby 'doll' or animals in these settings. These opportunities for boys to enact caring were of surprise to a couple of the participants who, through prior knowledge or assumption about particular students, did not expect them to behave in a caring way in front of others. These reactions highlight the fact that caring is associated with gender to the extent that nurturance is sometimes seen as a female trait, and girls are also reported as more inclined that boys to exhibit certain types of prosocial behaviours (Eisenberg \& Mussen, 1989). This points to a further interesting, and potentially beneficial aspect of providing opportunities to 'enact' caring in classrooms the potential to 'recreate' in others' eyes, and indeed in our own, the extent 
to which we are perceived as compassionate individuals. Cotton (2001) says that the teacher's goal should not be simply to produce a given behaviour, "but to help that child see himself or herself as the kind of person who is responsible and caring".

\section{Empathy and compassion transference}

There is potential, too within these relationships toward vulnerable others, to engineer a 'transference' of empathy and compassion to peers and others around us, through the development of more generalised prosocial dispositions. This was a core aim of the Roots of Empathy program, in which peer-related empathy was sought alongside empathy for the baby. Whilst human-oriented prosociality was not a deliberate focus within the Animal Club program, a growing base of research on classroom-based humane education programs suggests some connection between humane education programs, and the development of human-directed prosociality and empathy (Ascione, 1997; Faver, 2010). As noted by Kehret (2001, p. 44) "If we can teach children at a young age to treat animals humanely, we will have taken a huge step toward creating a better world. Compassion for animals leads to empathy for people".

\section{There is a benefit in exploring varied approaches to educating empathy and compassion, including efforts to address compassionate advocacy in schools}

In the next section, I briefly discuss three different approaches which have merit for fostering empathy and compassion, and which have been drawn from the case studies. These are teaching 'skills' to aid empathy and compassion development; explicitly teaching empathy and compassion as values concepts and 'character traits', and addressing social and global issues through compassionate advocacy. Specific attention has been devoted here to the third element, compassionate advocacy, as it is 
suggested that this dynamic is often overlooked in favour of addressing the interpersonal (as opposed to societal and global) potential of empathy and compassion.

\section{Teaching 'skills' to aid empathy and compassion development}

In the previous chapter, I made brief mention of the possibility that there are caring 'skills' which might be deliberately taught and practiced in order to increase children's potential to act in empathic and compassionate ways. Whilst in isolation these skills may not address the issue of caring motivation, they may still lay important groundwork for the development of prosociality. SEL 'skills' which have been addressed here as potentially complimentary to empathy learning include developing of emotional vocabulary, connecting thinking and feeling states, exploring temperament, and emotional regulation. Whilst SEL teaching requires skilful educators (Brunker, 2007; Weare, 2004) there are potentially some elements of this teaching which are within the abilities of all teachers, such as developing emotional understanding and vocabulary and exploring temperament differences. Other more advanced aspects of SEL teaching such as the fostering of healthy emotional expression and regulation may require targeted professional learning, so that teachers can develop strategies for navigating emotionally-oriented discussion in a safe and supportive manner.

Secondly, perspective taking has been referred to in this study as a core component of empathy, and potentially as an aid to compassion development. Perspective taking remains a potential which can be deliberately and consciously cultivated (Oliner \& Oliner, 1995). Elias and Arnold (2006, p. 168) note although it is easy enough to state that everyone sees the world differently: "Repeated and ongoing effort is needed to see the world through the eyes of others and to understand 
situations from diverse points of view". In the RoE program, perspective taking was encouraged through literature, guided observations of the baby, and through discussing and drawing about hypothetical scenarios. Other avenues for supporting perspective taking include role playing, open-ended moral dilemmas, and most simply, asking students to imagine themselves in the position of another (Reiman \& Dotger, 2008; Oliner \& Oliner, 1995).

\section{Teaching caring values as an explicit aim, through focusing on defining, analysing and enacting}

Previous discussion has briefly addressed the ways in which the RoE progam approaches empathy as an explicit aim, which was clearly recognised, defined and taught through the program curriculum. In these contexts, empathy and compassion can be interpreted as character traits or virtues, or referred to explicitly as 'ways of working' in classrooms. As noted previously, there is merit in addressing values explicitly because this approach ensures values teaching and learning become ubiquitous, and embedded in the consciousness within every school activity (DEEWR, 2008). An obvious benefit of approaching values teaching in this way is that educators will be given (or ideally can debate) a common understanding of how values will be defined and applied.

There are many sources who believe that addressing commonly held values and virtues is important. De Roche and Williams $(1998$, p. 2) for example, argue that there are commonly held values that children and youth need to learn, and that "by working together with families and community groups, we can identify these values, teach them, model them, and encourage young people to practice them". Obviously, empathy and compassion are addressed in this study as significant values for addressing with students. Yet there is sense too, in negotiating 
the form these values should take especially given that values such as compassion, can have a range of interpretations.

\section{Teaching compassionate advocacy}

Whilst there is benefit in exploring a range of values, and values teaching approaches, particular argument is offered at this point for the development of compassionate advocacy, as it has been termed here. I suggest that the potential of compassionate advocacy as a lens for exploring social and global issues deserves further exploration. In my opinion, our responsibilities to 'distant' others, and other issues of social and global importance often appear to take second place, behind approaches which focus on developing interpersonal skills and values. This bias toward the interpersonal domain in values learning is not surprising when faced with the realities of classroom life. Yet, as Nucci (2009) states, creating 'nice' students is not enough:

As educators, then, we would want to proudly work toward the development of "nice" people. But we would need to accomplish more than that if we are to meet our own ethical obligations as educators. Each generation inherits the socialmoral system of their parents. If as educators we simply teach these inherited moral and social norms, then we contribute to the perpetuation of whatever moral contradictions are contained in those social values (p. 3).

Now, more than any other time in our history, global issues are becoming a shared concern. The ability and motivation to reach out to others, and understand their experience will be an important step toward creating more optimistic futures. I suggest here that we must ensure that the values we adopt are not insular, but that as a society, we 
look to others - to global neighbours, oppressed groups and even others species, to make caring connections.

In these settings compassionate advocacy could focus on an appraisal of how to counter suffering, oppression or misfortune in specific settings, focusing primarily on developing options for compassionate action. Noddings (2010) suggests we can properly care about the needs and sufferings of people with whom we are unlikely to meet face-to-face, and that this focus on need is preferable to one based on rights, which are not uniformly acknowledged. The lens of compassion would seem to be particularly suited to addressing issues of global suffering, oppression or misfortune. Specific issues which are suggested as appropriate in these settings include education for social justice, environmental responsibility and peace.

In seeking to apply a lens of compassion to issues of global significance, a few matters need to be addressed specifically. Firstly, as acknowledged in the previous chapter, the practical issues in addressing fact, on one hand, and values on the other, dictate that whilst these endeavours are compatible, they should be accompanied by explicit reference to values positions, rather than leaving values as part of the 'hidden curriculum'.

Secondly, complexity is also an issue when addressing issues of global significance, and they can be multi-layered and even controversial. Soley (1996, p. 13) notes that it is understandable that everyone yearns for simple answers and solutions to conflicts, "Yet the truth is that there are no simple answers, because the political, economic and social questions that underlie conflicts are extremely complex". The extent to which opposing perspectives are analysed, clarified and settled on by students, will be dictated by the aims of educators. As noted in previous discussion, there would appear to be value in portraying the complexity 
embedded in these issues, providing these are explained in ways that are accessible to students, and that they allow for empathic and compassionate perspectives to be explored alongside other positions.

Finally, there is the issue of sadness in this suggested approach to compassionate advocacy, and the need to attend to this learning in a way that acknowledges feelings of sadness, sympathy or frustration as a normal, and potentially helpful experience in these settings. Indeed, "Looking through other people's eyes" involves an experience of reality that is sometimes intolerable, impossible, and painful" (Lampert, 2003, p. 18). There are some who see suffering as something which can be appropriately addressed with students, as noted by Weil (2004):

Some may think that exposing young people to the ills of the world is harmful, not helpful. I share the concern that young children must be protected from too much knowledge about the suffering in the world, but elementary school students can certainly be inspired to live with compassion and kindness. As our children reach middle and high school, however, they will undoubtedly begin to know about the challenges we confront on this planet, whether or not we teach them about it ourselves (p. 6).

Obviously in these settings, as with all values learning, the extent of children's emotional and cognitive maturity bears upon any approach (Goodman \& Lesnick, 2004). Some avenues for addressing students' feelings of sadness have been touched on briefly in this study including acknowledging and validating feelings of sadness and redirecting them into positive action.

Engaging with not-for-profit groups to support compassionate advocacy

As a final point, I suggest here that there are vast opportunities for engaging with not-for-profit groups in exploring compassionate 
advocacy. Some of the benefits for this approach can be discerned from the ways in which the Animal Club program was assisted through affiliation with the Voiceless Animal Club program, and also with respect to other animal organisations with which the clubs engaged. Three distinct benefits are suggested here. This approach provides access to knowledge with respect to social and global issues, to which teachers may not have access. Secondly, providing children with opportunities to engage with the activities of different not-for-profit groups opens up established pathways for helping 'distant' others, which are often focused on addressing 'grass-roots' problems, rather than tokenistic approaches to addressing social issues. Finally, a growing number of charities provide school-friendly resources and programs, which make explicit links to the academic potential of addressing topical social and global issues.

\section{The importance of attending to the cognitive, affective and behavioural elements of empathy and compassion in teaching these values}

The processes whereby one person can come to know the internal state of another and respond appropriately are of "enormous importance for our life together" (Batson, 2009, p. 11). In accepting the significance of educating empathic and compassionate dispositions, I have attempted to gain some insight into the process of educating these values by exploring the ways they might be interpreted. After looking at the cognitive, affective and behavioural elements of these values, I argue here that there is utility in addressing these elements specifically in the teaching of empathy and compassion. Attention to these three elements potentially militates against simplistic treatments of these concepts, which might construe them as simply 'warm and fuzzy' or watered-down versions of caring and kindness. Moreover, acknowledging empathic and compassionate behaviour as 
inherent to the process of teaching them, helps create a 'bridge' between moral 'knowing' and moral 'acting', and adds to their potential as powerful forms of caring education.

Whilst separate attention can be given to the presence of these elements in teaching caring values, this is not to say that they operate in mutually exclusive ways. Indeed, cognition and affect, in particular, form an 'inseparable nexus' (Lovat, et al., 2009, p. 11), and a variety of commentators have addressed the fact that emotion and learning should be addressed hand-in-hand (Chickering, 2006; Owen-Smith, 2004; Reigeluth, 1999; Stewart, 2007; Hall, 2005). Similarly, there is obvious utility in attending to both 'belief and behaviour' in affective learning (Straughan, 1989: De Rosa, 1984). Accordingly, the approach which is suggested here would be one which acknowledges the interrelatedness of these elements, and which gives attention to developing each of these components, (thinking, feeling and acting) in the course of teaching. As noted in the previous discussion, particular emphasis has been placed on opportunities to enact caring values, as this may support an important transition from merely teaching about values, to living them.

\section{Teachers should be supported to address caring values such as empathy and compassion with their students}

Whilst the role of the educator in each of these programs has not been addressed in detail, it is acknowledged that this is a critical factor within the success of these programs. Neilson $(2005$, p. 3) says that developing values requires admirable and skilful educators: "Admirable because with no other learning objective is it more obvious that one must be able to 'practice what one preaches' and skilful because the teaching of internal values and attitudes necessarily requires attention to subtle and pedagogical modes of learning". In the two case studies addressed in this study, the educators who 
taught these programs had skills which were vital in enabling them to implement these programs. The RoE instructors had knowledge of the program's curriculum as well as training in delivering social and emotional learning. The Animal Club teachers developed knowledge about animal welfare issues, and accessed resources which gave them advice on appropriate and sensitive approaches to teaching these issues. They were also able to draw on the experiences of like minded humane educators, through the website which was associated with the program. In both cases, educators were highly motivated individuals, who felt passionately about their programs.

As calls for schools to teach right and wrong gather momentum, it is important to reflect on what such calls may mean for the ordinary teacher (Haydon, 1997). It appears that some educators will lead efforts to include caring values in their schools, and for others this will come at the explicit urging of schools, or policy makers. Either way, it cannot be assumed that teachers will adopt these techniques without first having access to the training or resources to scaffold them in this task. At the very least, some guidance is needed about how to foster caring values with students, in order that this task be made more accessible to the average teacher. This undertaking will presumably have implications for teacher education, and school resourcing.

The benefits of supporting teachers in developing sound approaches to values teaching are obvious. There is reason to believe that well crafted values education has an enhancing effect on teaching, and may therefore represent a 'missing link' for quality teaching (Lovat \& Clement, 2008; Lovat, et al., 2009). Moreover, teaching is a 'caring' profession and there is reason to believe that many teachers enter the teaching profession "because they believe they could make a difference in the lives of students and thus 
contribute to society" (Hamberger 1997, p. 303). Weissbourd (2003, p. 5) notes that most teachers "have brought to this work their hearts and souls, and many have lost the belief that they can make a real difference in students' lives". Accordingly, by equipping teachers with the knowledge and resources to undertake values education successfully, this may contribute to a more successful and personally fulfilling experience of teaching.

\subsection{Limitations of the study}

As with any thesis there were limitations inherent to this project, and these should be kept in mind when seeking to extend the findings beyond this immediate context.

\section{Generalisability}

The issue of generalisability has been addressed by various commentators on case study research (Punch, 2009; Simons, 2009; Stake, 1995). They generally highlight the fact that case study research is oriented to illuminating context and specificity, rather than producing generalisation. There was intrinsic interest in exploring the two programs in this study further, given that they were unique, small in scale, and that little is known about them in education settings. Yet the case studies also have instrumental interest, because they were selected in order to offer insight into wider issues, namely empathy and compassion teaching. Punch (2009) notes that despite the highly contextualised nature of many case studies, in some instances, some forms of generalisation will be possible. This includes instances where an author creates abstract 'concepts' and 'propositions' as a result of the case, as opposed to purely descriptive accounts. It is argued here that despite the small number of participants, this discussion has targeted issues which have application beyond the immediate settings of the two programs described here. Indeed, the intention has been to seek insight into the wider issues of empathy and compassion teaching, and 
relationships of caring. With this in mind, some broader implications are envisaged beyond the immediate settings explored through this study.

\section{Study design}

The preceding discussion has addressed some observations and implications from these programs, based on conversations with teachers and instructors in the two programs. It is important to note that this is a small scale study, due to the timeframes and practical limitations of this study, as well as the small number of potential participants. It is also important to acknowledge that those participants who were approached for this project may have particularly positive attitudes toward the programs, and that their experiences may not, therefore, entirely reflect those of a wider crosssection of teachers in these settings. In the Roots of Empathy, the instructors spoken to were among the last educators who were still carrying out the program, and as such presumably held it in high regard. With the Animal Club, four of the five teachers spoken to had a relatively active presence within the Voiceless website, indicating that they were particularly engaged in the program. Despite these factors, the experiences described by teachers and instructors were not uniform, but were instead a reflection of a wide variety of backgrounds, and school settings. Moreover, whilst there is a possibility that teachers and instructors had a very favorable view of the programs, this would have a minimal impact on the specific implications which have been raised in this chapter.

\section{The lack of similar research}

The lack of similar research has formed an ongoing challenge in this study, due to an inability to locate it within an existing body of empirical literature. Where possible, some secondary sources have been drawn upon, yet their direct applicability is limited by a lack of congruence with the specific issues being addressed here. This means that the questions, findings and 
implications in this study have been guided with reference to sources which are relevant in a general sense, therefore limiting the extent to which this study could be compared against insights from other comparable studies. This study is therefore highly exploratory in nature.

\subsection{Recommendations for further research}

There were many 'knowledge gaps' encountered in the course of this study, the most pressing of which are addressed below, as possible avenues for future research.

\section{Exploring approaches to teaching empathy and compassion}

Once we have established that teaching values is desirable, it follows that we would want to teach them in informed ways (Kirschenbaum, 1994). Accordingly, it is suggested here that further research could usefully explore different approaches to empathy and compassion teaching with a view to informing a clearer picture of existing interpretations and practices in this area. In my reading of the literature on these two values, it was apparent that there is little information regarding instructional approaches to teaching them in classroom settings. Further investigation of these issues would add to our understanding of the array of different approaches to teaching these values.

Some broad implications have been drawn in this study, which would benefit from further exploration. Some interest has been directed in this chapter, toward the notion of compassionate advocacy in classrooms. Again, little information has been located on how this might be fostered, or the implications for this teaching within education for citizenship, peace, environmental responsibility and humane education. The potential to work alongside not-for-profit groups in informing and addressing this type of learning is another possible focus for future research efforts. 
Babies and animals as 'teachers' of empathy and compassion

This study has explored the significance or 'relationships of caring' which children have with vulnerable others, namely babies and animals. These relationships provide children with an engaging experience and present opportunities for experiential learning through opportunities to interact with babies and animals. To help develop these types of programs into a robust framework for caring education, it is important to explore further their potential to contribute to the development of more generalised prosocial dispositions. An exploration of this area would include an evaluation of the curriculum approaches which best contribute to fostering prosociality in these settings. Whilst not addressed specifically in this study, further research could also focus on the academic potential of undertaking this learning in schools.

Investigating links between values teaching and emotional literacy learning There appear to be many synergies (and shared aims) between values teaching and the field of social and emotional learning. Emotion is increasingly recognised as a critical aspect of all learning, yet it is also pertinent within teaching about values. Weissbourd (2003, p. 2), for example, notes:

Most of the talk about moral development in schools assumes that we can teach students to behave morally by instilling in them virtues and standards, a clear sense of right and wrong. This assumption ignores the fact that emotions are often the horse, values and virtues the rider trying to hang on.

In my reading of the literature on social, emotional and moral learning, relatively little attention has been directed toward the mutually reinforcing capacities of these two fields. Given the increasing attention devoted to the 
place of both of these fields in schools it would seem to make sense to further explore the ways in which they might interact.

\subsection{Final reflections}

There are competing demands in education. In an environment where different voices vie for a spot in the 'crowded curriculum', an argument is made here for prioritising the development of caring values as a critical investment in personal, social and global potential.

Education is the most obvious place for fostering caring values. In a practical sense, it is a central mission of schools to shape the academic and personal development of students, and one would assume that eleven years devoted to this task opens up vast possibility for the shaping of caring dispositions. Moreover, children undertake compulsory education at a period in their lives when personalities, attitudes and values are being rapidly shaped, making the education of caring values a timely, and critical undertaking.

The main motivation in this study has been to explore some possibilities for creating optimistic and humane futures, through the teaching of empathy and compassion. There is an assumption here, supported by the literature on empathy and compassion, that our ability to care about others, not only benefits children but also has profound implications for our common future. In accepting the importance of these values, I have argued that we would want to look closely at how they can be fostered in current and future generations of students.

In exploring this potential it is important to acknowledge current education realities and the fact that "schools find themselves at the interface between the relentless modernisation and marketisation of the educational system on the one hand and the social, emotional and behavioural fallout of pervasive human stress and distress on the other" (Harris 2008, p. 367). 
Clearly, in these settings it is important to provide support and training for teachers to address caring values with children, but it is also important that they have the encouragement and professional support, to ensure this critical task is not undertaken in isolation.

After reviewing the literature on empathy and compassion, some encouragement has been gained through a number of sources who believe that caring values can be deliberately nurtured in classrooms. A logical 'next step' in developing empathy and compassion into a robust framework for teaching, is to look closely at the varying ways they can be developed and strengthened across different contexts. Accordingly, this study represents an effort to look beyond empathy and compassion as admirable moral precepts, and focus on some specific ways they might be translated through practical teaching approaches.

Both of the programs addressed in this study offer insights into the process whereby children come to understand, and care for others. Some implications have been drawn from these programs, and are tentatively offered as a contribution to the (often diffuse) picture representing empathic and compassionate possibilities in education. Moreover, an important lesson can be gleaned through the extent to which these programs form an act of optimism in a small number of schools where they thrived, and where they represent a clear investment in the caring potential of children. In these settings, we are driven, not by the threat of despair, but by the hope for a more optimistic shared future. As noted by Cavanagh (1995) perhaps the time has come to stop lamenting the absence of compassion in our society and to attempt to rediscover it. 


\section{BIBLIOGRAPHY}

Allen, J. (2004). Sociology of education: Possibilities and practices. In J. Allen (Ed.), Searching for Hidden Potatoes! Social Science research in education (3rd ed., pp. 3-28). Melbourne: Social Science Press.

Areglado, R. (2001). Social and emotional learning: The future is now. In J. Cohen (Ed.), Caring classrooms/intelligent schools : the social emotional education of young children (p. 183-194). New York ; London: Teachers College Press.

Arluke, A. (2004). Childhood origins of supernurturance: The social context of early humane behavior. anthrozoos, 16(1), 3-27.

Ascione, F. (1997). Humane education research: Evaluating efforts to encourage children's kindness and caring toward animals. Genetic, Social, and General Psychology Monographs, 123(1), 59-78.

Ascione, F. (2004). Children and animals. Indiana: Purdue University Press.

Ayers, W. (2003). Who in the world am I? Reflections on the heart of teaching. Curriculum \& Teaching Dialogue, 5(1), 1-8.

Bailey, T. (2005). Teacher perceptions on the Roots of Empathy program. M.Ed. dissertation, University of Manitoba, Canada. Available from Dissertations \& Theses: Full Text. (Publication No. AAT MR08815).

Balcombe, J. (1999). Animals and society courses: A growing trend in postsecondary education. Society and Animals, 7(3), 229-240.

Batson, C. D. (2009). These things called empathy: Eight related but distinct phenomena. In J. Decety \& W. Ickes (Eds.), The Social Neuroscience of Empathy (p. 3-17). Massachusetts: MIT Press.

Batson, D., Early, S., \& Salvarani, G. (1997). Perspective taking: Imagining how another feels versus imagining how you would feel. Personality and Social Psychology Bulletin, 23(7), 751-758.

Bell, J. (2005). Doing your research project: A guide to first-time researchers in education, health and social justice (4th ed.). New York: Open University Press.

Benninga, J. S., Berkowitz, M. W., Kuehn, P., \& Smith, K. (2006). Character and academics: What good schools do. Phi Delta Kappa International, 87(6).

Berg, B. L. (2004). Qualitative research methods for the social sciences (5th ed.). Boston: Pearson.

Berkowitz, M., \& Bier, M. (2006). What Works in character education: A report for policy makers and opinion leaders.

Bierhoff, H.-W. (2005). The psychology of compassion and prosocial behaviour. In P. Gilbert (Ed.), Compassion: Conceptualisations 
research, and use in psychotherapy (p. 140-167). New York, NY: Brunner-Routledge.

Bierne, P., \& Alagappan, M. (2007). A note on pedagogy: Humane education making a difference. Journal for Critical Animals Studies, V(2), 1-16.

Blizek, W. (1999). Caring, justice, and self-knowledge. In K. A. Strike, N. Noddings \& M. S. Katz (Eds.), Justice and caring: the search for common ground in education (p. 93-109). New York: Teachers College Press.

Bogdan, R., \& Biklen, S. K. (2003). Qualitative research for education: An introduction to theory and methods (4th ed.). Boston, MA: Allyn and Bacon.

Borowiec, J. B., \& Langerock, N. L. (2002). Creating empathetic spaces. Curriculum \& Teaching Dialogue, 4(2), 79.

Brunker, N. (2007). Primary schooling and children's social emotional wellbeing: A teacher's perspective. Paper presented at the AARE.

Burgess, J. (2005). Empathy: Central to social, emotional, and academic achievement. In B. Bartlett, F. Bryer \& D. Roebuck (Eds.), Stimulating the 'action' as participants in participatory research. Volume 1 (p. 160-170). Griffith University, School of Cognition, Language and Special Education, 2005.

Burton, D. (2000). The use of case studies in social science research. In D. Burton (Ed.), Research Training for Social Sciences (p. 214-225). London: Sage.

Cain, G. (2007). A research study examining the impacts of the socioemotional learning program "Roots of Empathy" on classroom teachers in Western Australia. (Master's Thesis). Curtin University, Perth (Unpublished).

Campbell, E. (2001). Educating for a humane society. In J. Campbell (Ed.), Creating Our Common Future: Educating for Unity in Diversity ( $p$. 100-122). New York: Berghahn Books.

Carr, B. (1999). Pity and compassion as social virtues. Philosophy, 74, 411429. .

Caselman, T. (2007). Teaching children empathy: The social emotion: Lessons, activities and reproducible worksheets $(K-6)$ that teach how to "step into other's shoes". Chapin, SC: YouthLight, Inc.

Cavanagh, M. (1995). Rediscovering compassion. Journal of Religion and Health, 34(4), 317-327.

Cohen, J. (2001). Caring classrooms/intelligent schools: The social emotional education of young children. New York ; London: Teachers College Press.

Cotton, K. (2001). Developing empathy in children and youth. School Improvement Research. Series Close Up \# 13. Retrieved 12 December 2008 from http://www.nwrel.org/scpd/sirs/7/cu13.html 
Creswell, J. (1998). Five qualitative traditions of inquiry. In Qualitative Inquiry and Research Design: Choosing among five traditions (p. 4771): Sage, Thousand Oaks.

Crisp, R. (2008). Compassion and beyond. Ethical theory and moral practice, 11(3), 233-246.

Danaher, A., Brown, M., \& Slate, J. (2008). Character education and student connectedness: A Conceptual Analysis. Journal of Cognitive Affective Learning, 4(2), 13-25.

De Roche, E. F., \& Williams, M. M. (1998). Educating hearts and minds: A comprehensive character education framework. Thousand Oaks, Calif.: Corwin Press.

De Souza, M. (2005). Growing empathetic, compassionate, meaningful and hope-filled students: Re-discovering the spiritual dimension in education. New Horizons in Education, 113(November 2005), 41-52.

Decety, J., \& Lamm, C. (2009). Empathy versus personal distress. In J. Decety \& W. Ickes (Eds.), The Social Neuroscience of Empathy (p. 199-213). Massachusetts: MIT Press.

Decety, J., Michalska, K., Akitsuki, Y., \& Lahey, B. (2009). Atypical empathic responses in adolescents with aggressive conduct disorder: A functional MRI investigation. Biological Psychology, 80, 203-211.

Denzin, N. K., \& Lincoln, Y. S. (1994). Handbook of qualitative research. Thousand Oaks: Sage Publications.

Department of Education and Training (DET), Western Australia. (2005). The evaluation of Roots of Empathy in Western Australian Schools. Western Australia: Telethon Institute for Child Health Research.

DEST. (2006). Implementing the national framework for values education in Australian schools: Report of the values education good practice schools project - stage 1. Retrieved 8th December 2009. from http://www.curriculum.edu.au/values/val_vegps1_final_report,1638 1.html

DEEWR. (2008) At the heart of what we do: Values education at the centre of schooling: The values education good practice schools project Stage 2: Final report. Retrieved 8 December, 2009, from http://www.curriculum.edu.au/verve/_resources/VEGPSP_ 2_final_3.pdf.

Downey, M., \& Kelly, A. (1978). Moral education: Theory and practice. London: Harper and Row.

Eisenberg, N., \& Mussen, P. H. (1989). The roots of prosocial behavior in children. Cambridge [England] ; New York: Cambridge University Press.

Eisenberg, N., Fabes, R., Murphy, B., Karbon, M., Maszk, P., Smith, M., et al. (1994). The relationship of emotionality and regulation to 
dispositional and situational empathy-related responding. Journal of Personality and Social Psychology, 66(776-797).

Elias, M., \& Arnold, H. (Eds.). (2006). The educator's guide to emotional intelligence and academic achievement: Social-Emotional learning in the classroom. California: Thousand Oaks.

Epstein, T., \& Elias, M. (1996). To reach for the stars: How social-affective education can foster truly inclusive environments. Phi Delta Kappan, 78(2), 157.

Faver, C. (2010). School-based humane education as a strategy to prevent violence: Review and recommendations. Children and Youth Services Review, 32, 365-370.

Feshbach, N., \& Feshbach, S. (2009). Empathy and education. In J. Decety \& W. Ickes (Eds.), The Social Neuroscience of Empathy (p. 85-99). Massachusetts: MIT Press.

Feshbach, N., Feshbach, S., Fauvre, M., \& Ballard-Campbell, M. (1984). Learning to care curriculum: A curriculum for affective and social development. Illinois: Scott, Foresman.

Fien, J. (2003). Learning to Care: Education and compassion. Griffith University.

Forrester, G. (2005). All in a day's work: Primary teachers'performing' and 'caring'. Gender and Education, 17(3), 271-287.

Frakes, C. (2004). The virtue of compassion: Responding to suffering with equanimity. Ph.D. dissertation, State University of New York at Binghamton, New York. Retrieved April 16, 2009, from Dissertations \& Theses: Full Text.(Publication No. AAT 3150492).

Freakley, M., Burgh, G., \& Tilt-MacSporran, L. (2008). Values education in schools: A resource book for student inquiry. Camberwell, Vic.: ACER Press.

Freebody, P. (2003). Qualitative research in education: Interaction and practice. London: SAGE.

Friedland, J. (1999). Compassion as a means to freedom. The Humanist, July/August, 35-39.

Garbarino, J. (2007). Protecting children and animals from abuse. In J. Donovan \& C. Adams (Eds.), The feminist care tradition in animal ethics: A reader (p. 250-259). New York: Columbia University Press.

Garber, M. (2004). Compassion. In L. G. Berlant (Ed.), Compassion: The culture and politics of an emotion (p. 15-29). New York: Routledge.

Gillath, O., Shaver, P., \& Mikulincer, M. (2005). An Attachment - theoretical Approach to compassion and altruism In P. Gilbert (Ed.), Compassion: conceptualisations, research and use in psychotherapy (p. 121-148). London: Routledge.

Gillham, B. (2000). Case study research methods. London: Continuum. 
Gilligan, C. (1993). In a different voice: Psychological theory and women's development. Cambridge, Mass.: Harvard University Press.

Goldstein, A., \& Michaels, G. (1985). Empathy: Development, training and consequences. New Jersey: Lawrence Erlbaum Associates Inc.

Goleman, D. (1996). Emotional intelligence: Why it can matter more than IQ. London: Bloomsbury.

Goodman, J. F., \& Lesnick, H. (2004). Moral education: A teacher-centred approach. Boston: Pearson/A and B.

Gordon, M. (2003). Roots of Empathy: Responsive parenting, caring societies. Keio Journal of Medicine, 52 (4), 236-243.

Gordon, M. (2007). Roots of empathy: Changing the world, child by child (1st pbk. ed.). Toronto: T. Allen Publishers.

Gribble, J., \& Oliver, G. (1973). Empathy and education. Studies in Philosophy and Education, 8(1), 3-29.

Hamberger, N. M. (1997). From Personal to Professional Values: Conversations about conflicts. Journal of Teacher Education, 48(4), 301-310.

Hawthorne, M. (2008). Striking at the roots: A practical guide to animal activism. Winchester: $O$ Books.

Haydon, G. (1997). Teaching about values: A new approach. London ; Herndon, VA: Cassell.

Heath, H. (1995). Parents and their infant visit the classroom. In Education for Parenting. Philadelphia, PA. Retrieved 9 April 2009, from http://www.eric.ed.gov/ERICWebPortal/custom/portlets/recordDeta ils/detailmini.jsp?_nfpb=true\&_\&ERICExtSearch_SearchValue_0=ED4 37153\&ERICExtSearch_SearchType_0=no\&accno=ED437153.

Hill, B. (2001). Educating for moral responsibility. In J. Campbell (Ed.), Creating Our Common Future: Educating for Unity in Diversity (p. 6179). New York: Berghahn Books.

Hill, B. (1991). Values education in australian schools. Hawthorn, Vic.: ACER.

Hills, A. (1995). Empathy and belief in the mental experience of animals. Anthrozoos, 8(3), 132-142.

Hodges, S., \& Klein, K. (2001). Regulating the Costs of Empathy: The Price of Being Human Journal of Socio-Economics, 30, 437-452.

Hoffman, M. L. (2000). Empathy and moral development: Implications for caring and justice. Cambridge: Cambridge University Press.

Hollingsworth, L. (2003). REACH Beyond Tolerance: a framework for teaching children empathy and responsibility. (Issues In Child Development) Journal of Humanistic Counseling, Education and Development, 42(2), 139-151.

Hooker, C., Verosky, S., Germine, L., Knight, R., \& D’Esposito, M. (2008). Mentalizing about emotion and its relationship to empathy. Social Cognitive and Affective Neuroscience, 3(3), 204-217. 
Hunt, M. (1990). The compassionate beast: What science is discovering about the humane side of humankind (1st ed.). New York: Morrow.

Janesick, V. (2003). The choreography of qualitative research Design: Minuets, improvisations, and crystallization. In N. K. Denzin \& Y. S. Lincoln (Eds.), Strategies of qualitative inquiry (2nd ed., p. 46-79). Thousand Oaks, CA: Sage.

Jenni, K. (2005). The power of the visual. Animal Liberation Philosophy and Policy Journal, 3(1), 1-21.

Johnston, D. K. (2006). Education for a caring society: Classroom relationships and moral action. New York, NY: Teachers College Press.

Jones, G. (2006). Other research methods. In M. Walter (Ed.), Social research methods: An australian perspective (p. 307-343). Melbourne: Oxford University Press.

Jones, R. (2009). Framing the framework: Discourses in Australia's national values education policy. Educational Research for Policy and Practice, 8(1), 35-57.

Joseph, P., \& Efron, S. (2005). Seven worlds of moral education. Phi Delta Kappan, 525-533.

Kaufmann, M., \& Fitchett, J. (1999). One more thing for teachers to do? Why and how educators should develop students' empathy and humanity (American Humane Association Reprint 2002). Protecting Children, 15(2).

Kay, W. (1975). Moral education. London: George Allen and Unwin Ltd.

Kehret, P. (2001). Encouraging empathy: An author makes a case for teaching interpersonal skills. School Library Journal, 47(8 (August 2001)).

Kenan, S. (2009). The Missing Dimension of Modern Education: Values education. Educational Sciences: Theory and Practice, 9(1), 279-295.

Kessler, R. (2004). Education for integrity: Connection, compassion, and character. In R. T. Eisler \& R. Miller (Eds.), Educating for a culture of peace (p. 57-79). Portsmouth, NH: Heinemann.

Kirschenbaum, H. (1977). Advanced value clarification. La Jolla, Calif.: University Associates.

Kirschenbaum, H. (1994). 100 ways to enhance values and morality in schools and youth settings. Boston: Allyn and Bacon.

Knight, S., Vrij, A., Cherryman, J., \& Nunkoosing, K. (2004). Attitudes toward animal use and belief in animal mind. Anthrozoos, 1, 43-62.

Kohn, A. (1991). Caring kids: The role of schools. Phi Delta Kappan, 72(7), 496-506.

Kohn, A. (1990). The brighter side of human nature: Altruism and empathy in everyday life. New York: Basic Books. 
Kristjánsson, K. (2010). Educating moral emotions or moral selves: A false dichotomy? Educational Philosophy \& Theory, 42 (4), 397-409.

Lampert, K. (2003). Compassionate education: A prolegomena for radical schooling. Lanham, Md.: University Press of America.

Lancy, D. F. (1993). Qualitative research in education : An introduction to the major traditions. New York: Longman.

Lichtman, M. (2006). Qualitative research in education: A user's guide. Thousand Oaks: Sage Publications.

Lickona, T., Schaps, E., \& Lewis, C. (2007). Eleven principles of effective character education from http://www.character.org/elevenprinciples

Litvak-Miller, W., \& McDougall, D. (1997). The structure of empathy during middle childhood and its relationship to prosocial behavior. Genetic, Social \& General Psychology Monographs, 123(3).

Lovat, T. (2006). Values Education: The Missing Link in Quality Teaching. Paper presented at the The National Values Education Forum. Retrieved 11 April 2009, from, http://www.valueseducation.edu.au/values/val_articles,8884.html

Lovat, T., \& Clement, N. (2008). Quality teaching and values education: Coalescing for effective learning. Journal of Moral Education, 37(1), 1-16.

Lovat, T., Toomey, R., Clement, N., Crotty, R., \& Nielsen, T. (2009). Values education, quality teaching and service learning. Sydney: David Barlow Publishing.

Lovat, T., (2010). Synergies and Balance between Values Education and Quality Teaching. Educational Philosophy \& Theory, 42(4), 489-500.

Lumpkin, A. (2008). Teachers and role models: Teaching character and virtue. JOPERD, 79(2).

Martin, J. (2005). Perspectival selves in interaction with others: Re-reading G.H. Mead's social psychology. Journal for the Theory of Social Behaviour, 35(3).

Matthews, S., \& Herzog, H. (1997). Personality and attitudes toward the treatment of animals. Society and Animals, 5(2), 169-175.

Maxwell, B. (2006). Naturalized compassion: A critique of Nussbaum on literature as education for compassionate citizenry. Journal of Moral Education, 35(3), 335-352.

May, K. (1989). Interview techniques in qualitative research: Concerns and challenges. In J. Morse (Ed.), Qualitative Nursing Research: A Contemporary Dialogue (pp. 171-183). Rockville: Aspen Publishers.

MCEETYA. (2008). Melbourne declaration on educational goals for young Australians. Melbourne: MCEETYA. Retrieved $8^{\text {th }}$ January 2010 from http://www.curriculum.edu.au/verve/_resources/National_Declarati on_on_the_Educational_Goals_for_Young_Australians.pdf 
McGaghie, W., Mykto, J., Brown, N., \& Cameron, J. (2002). Altruism and compassion in the health professions: A search for clarity and precision. Medical Teacher, 24(4).

Mehus, E. (2001). Raising children who think for themselves. Oregon: Beyond Words Publishing.

Melson, L. G. (2001). Why the wild things are: Animals in the lives of children. Cambridge, MA: Harvard University Press.

Mendl, M., \& Paul, E. (2004). Consciousness, emotion and animal welfare: Insights from cognitive science Animal Welfare, 13(Supplement 1), 17-25.

Merriam, S. (1998). Qualitative research and case study applications in education (2nd ed.). San Francisco: Jossey-Bass Publishers.

Mitchell, J. (2004). Teaching about worldviews and values. Victoria: The Council for Christian Education in Schools.

Moreno, A. J., Klute, M. M., \& Robinson, J. (2008). Relational and Individual resources as predictors of empathy in early childhood. Social Development, 17(3), 613 - 637.

Mowry, S. (2007). Integrating character across the curriculum. In M. Schwartz (Ed.), Effective character education: A guidebook for future educators (1st ed., pp. 92-122). Boston: MHHE.

Muldoon, J., Williams, J., Lawrence, A., Lakestani, N., \& Currie, C. (2009). Promoting a 'duty of care' towards animals among children and young people: A literature review and findings from initial research to inform the development of interventions. Retrieved 12 January 2010 from http://www.education.ed.ac.uk/cahru/publications/reports_downlo ads/Defra_Yr1Report_Sep09.pdf

Myers, G. (1998). Children and animals: Social development and our connections to other species. Boulder, Colo.: Westview Press.

Myers Jr, O. (1996). Child-animal interaction: Nonverbal dimensions. Society and Animals, 4(1), 19-35.

Nielsen, J., \& Delude, L. (1989). Behavior of young children in the presence of different kinds of animals. Anthrozoos, 3(2), 119-129.

Nielsen, T. W. (2005). Values education through thinking, feeling and doing. The Social Educator, 23(No.2, August).

Noddings, N. (1995). Teaching themes of care. Phi Delta Kappan, 76(3) 675679.

Noddings, N (1992) The challenge to care in schools: An Alternative Approach to Education. Advances in Contemporary Educational Thought series, vol. 8. New York: Teachers College Press.

Noddings, N. (2004). War, critical thinking, and self-understanding. Phi Delta Kappan, 85(7), 488-495. 
Noddings, N. (2010). Moral Education in an Age of Globalization. Educational Philosophy \& Theory, 42(4), 390-396.

Nucci, L. (2007). Creating a foundation. In M. Schwartz (Ed.), Effective character education: A guidebook for future educators (1st ed., pp. 24-48). Boston: MHHE.

Nucci, L. P. (2009). Nice is not enough: Facilitating moral development. Upper Saddle River, N.J.: Merrill/Pearson.

Nussbaum, M. C. (2001). Upheavals of thought: The intelligence of emotions. New York ; Cambridge: Cambridge University Press.

Oliner, P. M., \& Oliner, S. P. (1995). Toward a caring society: Ideas into action. Westport, Conn.: Praeger.

Opie, C., \& Sikes, P. J. (2004). Doing educational research: A guide to firsttime researchers. London: SAGE.

Ozinga, J. R. (1999). Altruism. Westport, Conn. ; London: Praeger.

Park, J. (2003). The emotional literacy handbook: Promoting whole-school strategies. London: David Fulton Publishers in association with Antidote, Campaign for Emotional Literacy.

Parry, T. (2007). Developing emotional literacy: The Roots of Empathy program. Every Child, 13(4), 28-29.

Pattnaik, J. (2004). On behalf of their animal friends: Involving children in animal advocacy. Childhood Education, Winter, 95-100.

Pence, G. (1983). Can compassion be taught? Journal of Medical Ethics, 9, 189-191.

Phillips, L. (2003). Nurturing empathy. Art Education, 56(4), 45-50.

Pizarro, D. (2000). Nothing more than feelings? The role of emotion in moral Judgment. Journal for the Theory of Social Behaviour, 30(4), 355-375.

Preston, S., \& de Waal, F. (2002). Empathy: Its ultimate and proximate bases. Behavioral and Brain Sciences, 25, 1-72.

Punch, K. (2009). Introduction to research methods in education. London: SAGE.

Rapley, T. (2004). Interviews. In C. Seale, G. Gobo, J. Gubrium \& D. Silverman (Eds.), Qualitative research practice (pp. 15-32). London: SAGE.

Reigeluth, C., \& Martin, B. (1999). Affective education and the affective domain. In C. Reigeluth (Ed.), Instructional-design Theories and Models: A new paradigm of instructional theory (pp. 485-511). New Jersey: Lawrence Erlbaum Associates, Inc.

Reiman, A., \& Dotger, B. (2008). What does innovation mean for moral educators? Journal of Moral Education, 37(2), 151-164.

Reiss, M. J. (2003). Science education for social justice In C. Vincent (Ed.), Social Justice, Education and Identity (pp. 153-166). New York: Routledge.

Rice, J. (1995). The kindness curriculum: Introducing young children to loving values. St. Paul, MN 
Riley, J. (1990). Getting the most from your data: A handbook of practical ideas on how to analyse qualitative data. Bristol: Technical and Educational Services.

Ritchie, J., \& Lewis, P. (2004). Qualitative research practice. London: Sage.

Rowan, L., Gauld, J., Cole-Adams, J., \& Connolly, A. (2007). Teaching values. Marrickville, N.S.W.: Primary English Teaching Association.

Roots of Empathy (2010) About our program. Retrieved 3rd February 2010, from http://www.rootsofempathy.org/ProgDesc.html

Roots of Empathy. (2009). What is the Roots of Empathy? Retrieved November 2009, from http://www.rootsofempathy.org/roots_new_site/Video.html

Roots of Empathy. (2004). Roots of Empathy in Action. Retrieved 22 April 2009, from http://www.rootsofempathy.org/documents/RootsofEmpathyin Action06604.pdf

Ruiz, P., \& Vallejos, R. (1999). The role of compassion in moral education. Journal of Moral Education, 28(1), 5-17.

Ryan, G., \& Bernard, H. (2003). Techniques to identify themes. Field Methods, 13(1), 85-109.

Salmon, S. (2003). Teaching empathy: The PEACE Curriculum. Reclaiming children and youth, 12(3), 167-173.

Schertz, M. (2007). Avoiding 'passive empathy' with philosophy for children. Journal of Moral Education, 36(2), 185-198.

Schuitema, J., Dam, G. t., \& Veugelers, W. (2007). Teaching strategies for moral education: A review. Journal of Curriculum Studies, 40(1), 69 89.

Selby, D. (1993). Earthkind: Teacher's handbook on humane education. Staffordshire: Trentham Books.

Shaw, G. (2007). Values, a hot topic in a changing environment. Eingana, $30(2)$.

Shaw, L., Batson, D., \& Todd, M. (1994). Empathy avoidance: Forestalling feeling for another in order to escape the movitational consequences. Journal of Personality and Social Psychology 67(5), 879-887.

Silverman, D. (2006). Interpreting qualitative data: Methods for analyzing talk, text and interaction (3rd ed.). London: SAGE.

Simons, H. (2009). Case study research in practice. London: SAGE.

Slote, M. A. (2007). The ethics of care and empathy. London ; New York: Routledge.

Snape, D., \& Spencer, L. (2004). The foundations of qualitative research. In J. Ritchie \& P. Lewis (Eds.), Qualitative Research Practice (pp. 1-23). London: Sage. 
Snow, N. (1991). Compassion. American Philosophical Quarterly, 28(3), 195205.

Soley, M. (1996). It it's controversial, why teach it? Social Education, 60(1), 9-14.

Soren, R. (2001). Teaching emotions to young children. Educare News(October), 40-41.

Sprecher, S., \& Fehr, B. (2005). Compassionate love for close others and humanity. Journal of Social and Personal Relationships, 22, 629-651.

Stake, R. E. (1995). The art of case study research. Thousand Oaks: Sage Publications.

Stake, R. E. (2000). Case studies. In N. K. Denzin \& Y. S. Lincoln (Eds.), The Handbook of Qualitative Research (2nd ed., pp. 435-454). Thousand Oaks, Calif.: Sage Publications.

Stake, R. E. (2006). Multiple case study analysis. New York: Guilford Press.

Stewart, T. (2007). Intertwining the emotional and civic: Affective impacts of mandatory community service-learning on adolescent dispositions toward future civic engagement. Journal of Cognitive Affective Learning, 3(2), 18-28.

Strauss, A. L., \& Corbin, J. M. (1998). Basics of qualitative research: Techniques and procedures for developing grounded theory (2nd ed.). Thousand Oaks: Sage Publications.

Teich, N. (1994). Teaching empathy through cooperative learning. In A. G. Brand \& R. L. Graves (Eds.), Presence of mind: Writing and the domain beyond the cognitive (pp. 143-155). Portsmouth, NH: Boynton/Cook Pub.

The Learning Partnership. (n.d.) Program Overview. In Baby Matterz. Retrieved 2 February 2010, from http://www.babymatterz.com/

Thompson, K., \& Gullone, E. (2003). Promotion of empathy and prosocial behaviour in children through humane education. Australian Psychologist, 38(3), 175-182.

Thornberg, K., Hoffman, S., \& Remeika, C. (1991). Youth at risk, society at risk. The Elementary School Journal, 91(3), 199-208.

Todd, S. (2003). Learning from the other: Levinas, psychoanalysis, and ethical possibilities in education. Albany: State University of New York Press.

Toomey, R. (2006). Values as the centrepiece of the school's work - $A$ discussion paper on learnings from VEGPSP Stage 1. Paper presented at the Prepared for the First Briefing Session of the Values Education Good Practice Schools Project - Stage 2. Retrieved 2 February 2009 from http://www.curriculum.edu.au/values/val_articles,8884.html

Trentecoste, S. (2006). Implementing compassion through instruction to secondary students using a multiple intelligence approach in understanding the massacre at Wounded Knee in 1890 and the liberation of the Nazi concentration camps in 1945. D.A. dissertation, 
State University of New York at Albany, United States - New York. Available from Dissertations \& Theses: Full Text.(Publication No. AAT 3209583).

Tronto, J. C. (1993). Moral boundaries: A political argument for an ethic of care. New York: Routledge.

Tudor, S. K. (2001). Compassion and remorse: Acknowledging the suffering other. Leuven: Peeters.

Tulloch, G \& Verrinder, J (2007) Learning to Care: Education for Compassion: Griffith University, Queensland Australia. Retrieved 19 March 2009, from http://www.voiceless.org.au/Education/Misc/Humane_Education.ht $\mathrm{ml}$

Underwood, L. (2009). Compassionate love: A framework for research In B. A. Fehr, S. Sprecher \& L. Underwood (Eds.), The science of compassionate love: theory, research, and applications (p. 3-25). Malden, MA ; Oxford: Wiley-Blackwell.

Varkera, T., Devillya, G, Ward, T., \& Beech, A. R. (2008). Empathy and adolescent sexual offenders: A review of the literature. Aggression and Violent Behavior, 13(4), 251-260.

Vriens, L. (2000). Moral education as an answer to violence. Curriculum and Teaching 15(2), 69-79.

Watson, J., \& Greenberg, L. (2009). Empathic resonance. In J. Decety \& W. Ickes (Eds.), The Social Neuroscience of Empathy (p. 123-127). Massachusetts: MIT Press.

Watson, M., \& Benson, K. (2007). Creating a culture for character. In M. Schwartz (Ed.), Effective character education : a guidebook for future educators (1st ed., p. 48-92). Boston: MHHE.

Weare, K. (2004). Developing the emotionally literate school. London: Paul Chapman Pub.

Weil, Z. (2004). The power and promise of humane education. Gabriola Island, BC: New Society Publishers.

Weissbourd, R. (2003). Moral teachers, moral students. The Best of Educational Leadership. 2002-2003, 60(6), 6-11. Retrieved 11 January 2009, from http://www.valueseducation.edu.au/values/val_articles,8884.html

Whitebrook, M. (2002). Compassion as a political value. Political Studies, 50, 529-544.

Wiersma, W. (2000). Research methods in education: An introduction (7th ed.). Boston: Allyn and Bacon.

Wringe, C. (2006). Moral education: Beyond the teaching of right and wrong. Dordrecht: Springer.

Wuthnow, R. (1991). Acts of compassion: Caring for others and helping ourselves. Princeton, N.J.: Princeton University Press. 
Yin, R. K. (2009). Case study research: Design and methods (4th ed.). Thousand Oaks, California: Sage.

Zeece, P. (2009). Using current literature selections to nurture the development of kindness in young children. Early Childhood Education, 36(5), 447-452.

Zins, J., Bloodworth, M., Weissberg, R., \& Walberg, H. (2007). The scientific base linking social and emotional learning to school success. Journal of Educational and Psychological Consultation, 17(2\&3), 191-210.

Zins, J., \& Elias, M. (2008). Social and emotional learning: Promoting the development of all students. Journal of Educational and Psychological Consultation, 17(2\&3), 233-255. 


\section{University Library}

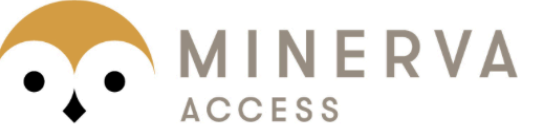

A gateway to Melbourne's research publications

Minerva Access is the Institutional Repository of The University of Melbourne

Author/s:

Gaastra, Avril Anne

Title:

Animals and babies: how the vulnerable teach us empathy and compassion

Date:

2010

Citation:

Gaastra, A. A. (2010). Animals and babies: how the vulnerable teach us empathy and compassion. Masters Research thesis, Melbourne Graduate School of Education, The University of Melbourne.

Persistent Link:

http://hdl.handle.net/11343/35619

\section{Terms and Conditions:}

Terms and Conditions: Copyright in works deposited in Minerva Access is retained by the copyright owner. The work may not be altered without permission from the copyright owner. Readers may only download, print and save electronic copies of whole works for their own personal non-commercial use. Any use that exceeds these limits requires permission from the copyright owner. Attribution is essential when quoting or paraphrasing from these works. 